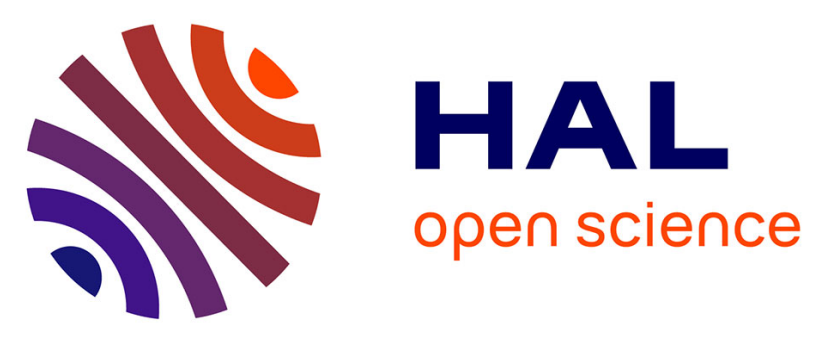

\title{
Tuning of interfacial charge transport in polyporphine/phthalocyanine heterojunctions by molecular geometry control for an efficient gas sensor
}

Abhishek Kumar, Nada Alami Mejjati, Rita Meunier-Prest, Anna Krystianiak, Olivier Heintz, Eric Lesniewska, Charles H. Devillers, Marcel Bouvet

\section{To cite this version:}

Abhishek Kumar, Nada Alami Mejjati, Rita Meunier-Prest, Anna Krystianiak, Olivier Heintz, et al.. Tuning of interfacial charge transport in polyporphine/phthalocyanine heterojunctions by molecular geometry control for an efficient gas sensor. Chemical Engineering Journal, 2022, 429, pp.132453. 10.1016/j.cej.2021.132453 . hal-03368969

\section{HAL Id: hal-03368969 \\ https://hal.science/hal-03368969}

Submitted on 7 Oct 2021

HAL is a multi-disciplinary open access archive for the deposit and dissemination of scientific research documents, whether they are published or not. The documents may come from teaching and research institutions in France or abroad, or from public or private research centers.
L'archive ouverte pluridisciplinaire HAL, est destinée au dépôt et à la diffusion de documents scientifiques de niveau recherche, publiés ou non, émanant des établissements d'enseignement et de recherche français ou étrangers, des laboratoires publics ou privés. 


\section{Graphical abstract}

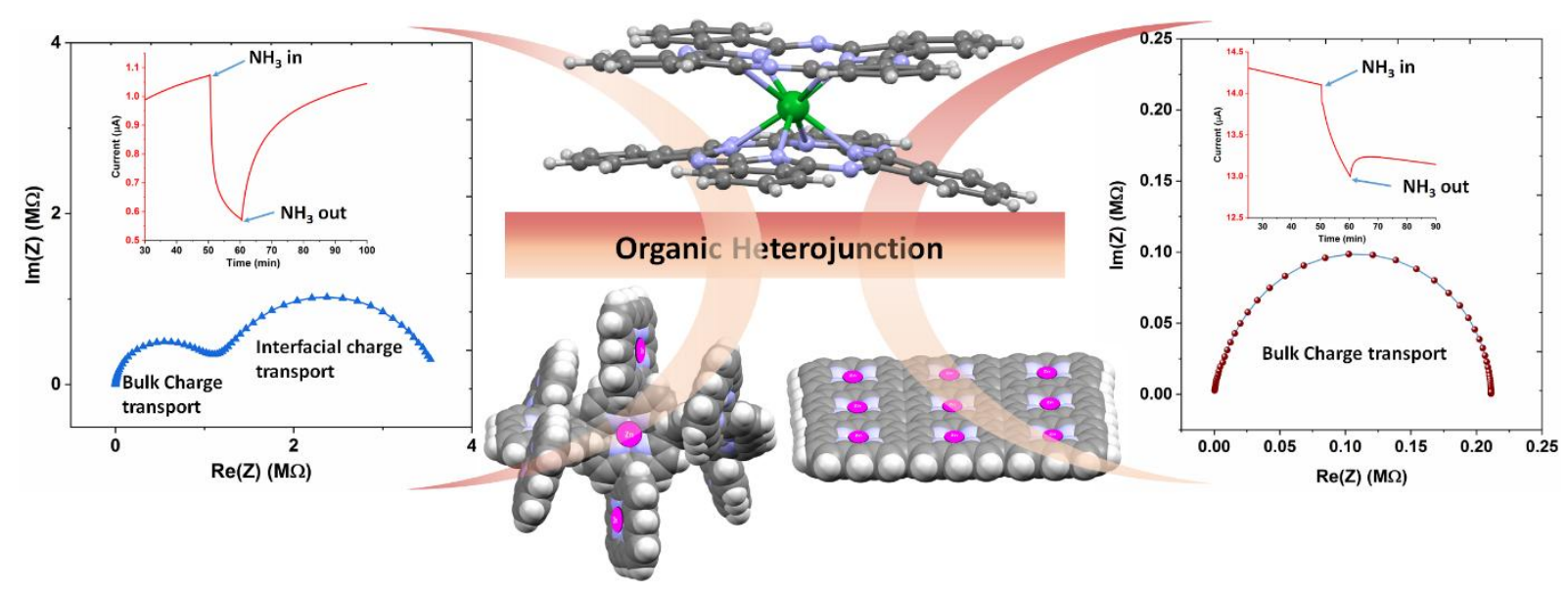




\section{Tuning of interfacial charge transport in polyporphine/phthalocyanine heterojunctions by molecular geometry control for an efficient gas sensor}

Abhishek Kumar ${ }^{1} *$, Nada Alami Mejjati ${ }^{1}$, Rita Meunier-Prest ${ }^{1}$, Anna Krystianiak ${ }^{2}$, Olivier Heintz $^{2}$, Eric Lesniewska ${ }^{2}$, Charles H. Devillers ${ }^{1}$, Marcel Bouvet ${ }^{1}$

${ }^{1}$ Institut de Chimie Moléculaire de l'Université de Bourgogne, UMR CNRS 6302, Université Bourgogne Franche-Comté, 9 Avenue Alain Savary, Dijon Cedex 21078, France

${ }^{2}$ Laboratoire Interdisciplinaire Carnot de Bourgogne (LICB), UMR CNRS 6303, Université Bourgogne Franche-Comté, 9 avenue Alain Savary, 21078 Dijon cedex, France

Email adresses and ORCID number of authors (corresponding authors emails are marked with asterisk)

*Abhishek.Kumar@u-bourgogne.fr (ORCID no. 0000-0002-4306-9644)

Nadaalamimejjati1@gmail.com

Maria-Rita.Meunier-Prest@u-bourgogne.fr (ORCID no. 0000-0001-5597-3879)

Anna.Krystianiak@u-bourgogne.fr (ORCID no. 0000-0003-3039-1412)

Olivier.Heintz@u-bourgogne.fr (ORCID no. 0000-0001-5512-4973)

eric.lesniewska@u-bourgogne.fr (ORCID no. 0000-0002-8027-7223)

*Charles.devillers@u-bourgogne.fr (ORCID no. 0000-0001-9078-7035)

Marcel.bouvet@u-bourgogne.fr (ORCID no.0000-0002-2272-6633) 
Abstract: Owing to high interfacial conductivity, organic heterostructures hold great promises to augment the electrical performances of electronic devices. In this endeavor, the present work reports fabrication of novel polyporphine/phthalocyanine heterostructures and investigates the modulation of charge transport induced by structural change of polyporphine and its implication on ammonia sensing properties. Polyporphines materials are electrosynthesized by oxidation of zinc(II) porphine monomer that corresponds to the fully unsubstituted porphyrin. At less-positive anodic potential, low conducting meso,meso-singlylinked type-1 polymer (pZnP-1) is formed in which a monomer unit stays orthogonal to its neighbors. At higher anodic potential, monomer units are fused in the $2 \mathrm{D}$ plane to produce $\beta, \beta$-meso-meso- $\beta, \beta$-triply-fused type-2 polymer ( $\mathrm{pZnP}-2)$, having a $\pi$-conjugated structure and high conductivity. Association of these polymers in organic heterojunction devices with lutetium bis-phthalocyanine $\left(\mathrm{LuPc}_{2}\right)$ reveals non-linear current-voltage (I-V) characteristics typical for interfacial accumulation of charges in the heterostructure for $\mathrm{pZnP}-1$ and a linear I$\mathrm{V}$ behavior for $\mathrm{pZnP}-2$. Characterization of these heterojunctions by impedance spectroscopy further confirms the predominance of interfacial charge transport in $\mathrm{pZnP}-1 / \mathrm{LuPc}_{2}$ which is improved with increasing bias, while largely bulk charge transport independent of bias prevails in $\mathrm{pZnP}-2 / \mathrm{LuPc}_{2}$ device. Different regimes of charge transport influence ammoniasensing properties of the devices, such that $\mathrm{pZnP}-1 / \mathrm{LuPc}_{2}$ demonstrates highly sensitive, reversible and stable response, while $\mathrm{pZnP}-2 / \mathrm{LuPc}_{2}$ shows low and unstable response.

Keywords: Organic heterojunction, Gas sensor, Polyporphine, Electrochemistry, Molecular material, Impedance spectroscopy 


\section{Introduction}

Organic heterostructures of $\pi$-conjugated materials have revolutionized the technological innovations in organic electronic researches. The key motivation, inspiring the wide scale use of organic heterostructures is the associated organic heterojunction effects [1] in which the opposite charge carriers electrons $\left(\mathrm{e}^{-}\right)$and holes $\left(\mathrm{h}^{+}\right)$are accumulated at the interface, owing to the difference in workfunction of the organic semiconductors in the heterostructure. Such accumulation provides a continuous conduction channel in the heterostructure film in contrast to a discrete pathway commonly observed in organic semiconductors [2], enhancing the interfacial conductivity to the order observed in metallic conductors [3]. In the recent years, these materials have attracted numerous interests in improving the performances of organic semiconductors based gas sensors. The majority of organic semiconductor thin films usually suffer from low carrier density, producing inferior gas sensors response. Moreover, adsorption of molecular oxygen and water, which act as traps for mobile electrons in the film [4, 5], badly affects the reversibility and lifetime of sensors. Organic heterostructures bring solutions to these problems by enhancing the conductivity of the sensing layer and protecting the conduction channel of the device from undesired charge trappings.

Among the advancements made in organic heterojunction based gas sensors, majority of heterostructures are based on Metal Phthalocyanines (MPc) [6]. This preference is inspired from the diverse semiconducting properties displayed by these macrocycles in their thin films by the change of either the central metal [7] or the peripheral substituents [8]. An Organic Field-Effect Transistor (OFET) having a bilayer of p-type CuPc and n-type dioctyl perylene tetracarboxylic diimide as sensing layer exhibited $c a$. 10-fold enhancement in sensitivity towards $\mathrm{NO}_{2}$ compared to $\mathrm{CuPc}$ thin films [9], highlighting the important role played by the organic heterojunction. $\mathrm{NO}_{2}$ sensitivity also improved by increasing the number of 
heterojunctions in the OFET devices as exemplified for a trilayer heterostructures based on vanadyl phthalocyanine, para-hexaphenyl and $N, N$-diphenylperylene tetracarboxylic diimide [10]. Other than layered configurations, OFET devices having a homogeneous blend of CoPc or $\mathrm{CuPc}$ with tris(pentafluorophenyl)borane were investigated to detect reducing gases like $\mathrm{NH}_{3}$ [11]. The device reported decrease in the drain current upon $\mathrm{NH}_{3}$ exposure as expected for a p-type conduction channel with a relative response (RR) of $13 \%$ for $450 \mathrm{ppb}$ of $\mathrm{NH}_{3}$ and a detection limit of $350 \mathrm{ppb}$. Besides OFET, gas sensing properties of bilayer heterostructures have been also investigated in Molecular Semiconductor-Doped Insulator (MSDI) devices [12], consisting of a high conducting organic semiconductor as the top layer and a low conducting semiconductor as the sublayer interfacing with electrodes. In this configuration, difference in conductivity of the two layers maximizes the exploitation of organic heterojunction effects at the interface. The high sensitivity towards $\mathrm{NH}_{3}$ and robustness of such devices were exemplified in our recent works [6]. Most of these devices used a high conducting double decker lutetium bisphthalocyanine $\left(\operatorname{LuPc}_{2}\right)$ as top layer and a low conducting sublayer among $\mathrm{Cu}\left(\mathrm{F}_{16} \mathrm{Pc}\right), \mathrm{Cu}\left(\mathrm{F}_{8} \mathrm{Pc}\right)$, alkylthio-tetrasubstituted $\mu$-nitrido diiron phthalocyanines and perylene diimide derivatives, exhibiting detection limit down to $140 \mathrm{ppb}$ and high tolerance to potential interferants [13-16]. We also reported a modified MSDI heterojunction by having two identical lateral interfaces in the heterostructures, which was termed as Double Lateral Heterojunction (DLH) [17, 18]. Such devices based on low conducting poly(2,5-dimethoxyaniline) and poly(2,3,5,6-tetrafluoroaniline) in combination with $\mathrm{LuPc}_{2}$ demonstrated high sensitivity towards $\mathrm{NH}_{3}$. To widen the scope of materials in heterojunction devices other than MPc, a homologue Metalloporphyrinoid (MPor) is a natural choice.

In recent years, MPor have found increasing attention in gas sensors [19], owing to their tunable semiconducting properties and specificity in the gas adsorption. For instance, 
chemiresistors based on nanotubes of MPor (M: Co, Zn) derivatives, containing 4hydroxyphenyl, 4-chlorophenyl [20] and 4-aminophenyl [21] substituents displayed high sensitivity towards $\mathrm{NO}_{2}$ with a detection limit up to $500 \mathrm{ppb}$ and faster sorption kinetics. Similarly, a conductometric sensor based on spin-coated tetraphenyl bis-porphyrin and its zinc derivative on gold surface was studied for detecting $\mathrm{NH}_{3}$, exhibiting good reversibility and faster response/recovery kinetics [22, 23]. Recently, a nanoelectronic sensor having a single nanofiber of pyridyl-substituted ZnPor spanned across the sensor electrodes was reported for the sensitive detection of $\mathrm{H}_{2} \mathrm{O}_{2}$ [24]. Other than chemiresistors, Di Natale et al. investigated a series of substituted MPor materials in OFET devices to detect organic vapors [25]. Despite these reports of MPor based chemosensors, their sensing performances are inferior to MPc heterostructures, which is mainly attributed to low conductivity of substituted porphyrin thin films. To overcome this limitation, two strategies are worth mentioning. The conductivity of MPor films can be improved by extending $\pi$-conjugation in the macrocycle through polymerization. In another approach, MPor can be combined to other organic semiconductors such as MPc in organic heterostructures to benefit from high interfacial conductivity. Recently, we investigated this approach in MSDI device configuration having a top layer of high conducting polyporphyrins (from nickel(II) 5,15-(diphenyl)porphyrin and nickel(II) 5,15-(dimesityl)porphyrin monomers) grown by Chemical Vapor Deposition (CVD) over a low conducting films of $\mathrm{CuPc}$ or $\mathrm{Cu}\left(\mathrm{F}_{16} \mathrm{Pc}\right)$ [26]. These devices revealed large enhancement in thin film conductivity, at first by polymerization, with a further boost by the organic heterojunction effect as well as high sensitivity towards $\mathrm{NH}_{3}$ (detection limit 228 $\mathrm{ppb}$ ). However, the use of expensive CVD method, requiring large amount of reactant monomer is a drawback. Therefore, search for a low-cost method of polyporphyrin synthesis and its film processing in sensing devices, requiring small amount of reactant monomer is of paramount importance. 
Recently, porphyrin polymers were synthesized by electropolymerization approach through oxidative $\mathrm{C}-\mathrm{C}$ coupling, using unsubstituted metal porphyrin, commonly termed as porphine as a building block [27, 28]. Metalloporphines (MP) are the simplest MPor, having twelve free meso and $\beta$-positions (Fig. 1a). At low positive potential (mild oxidation), MP monomers (Fig. 1a, $\mathrm{M}=\mathrm{Mg}(\mathrm{II})$ or $\mathrm{Zn}(\mathrm{II})$ ) are linked through $\mathrm{C}-\mathrm{C}$ coupling at the mesoposition [29], forming the "Type 1" polyporphine (Fig. 1b) in which each monomer unit is orthogonal to its neighbor in order to minimize the steric hindrance. Previous MALDI-TOF mass spectrometry analyses of the solution that resulted from the extraction of electrodeposited type $1 \mathrm{Mg}$ (II) polyporphine with tetrahydrofuran (THF) solvent showed that the soluble part of the polymer corresponded to small oligomers, from 3 to 9 monomer units [28]. Besides, a detailed analysis and simulation of the isotopic patterns that where observed on the mass spectrum confirmed that only one bond was observed between two monomer units. Moreover, UV-visible spectroelectrochemistry [30] and electrochemical quartz crystal microbalance [31] experiments demonstrated that the number of covalent bonds varies from 2.2 to 2.4 per monomer unit. That means that type 1 polymer exhibits mainly a linear and/or a zig-zag arrangement, with only sporadic ramification centers. On the other hand, application of higher positive potential (strong oxidation) causes multiple C-C couplings at meso and $\beta$ positions, resulting in ring fusion of neighboring MP monomers in the 2D plane, causing extension of $\pi$-conjugation and generating high conducting "Type 2" polymer (Fig. 1c) [32]. Until now, only $\mathrm{MgP}$ was used as a starting monomer for polyporphines synthesis, which is mainly ascribed to its relatively facile synthesis method, its good solubility in organic solvents and sufficiently low oxidation potential [33, 34]. Although, zinc(II) and cobalt(II) polyporphine films were obtained recently by some of us but these were achieved by the ion replacement of $\mathrm{Mg}(\mathrm{II})$ in the polymeric film [35-37]. 
Herein, we report in situ electropolymerization approach to synthesize polyporphine, directly on the sensor electrodes surface from ZnP precursor. The obtained polyporphines film is combined with a high conducting $\mathrm{LuPc}_{2}$ film in a $\mathrm{DLH}$ device configuration and its $\mathrm{NH}_{3}$ sensing performances are investigated. There are three key novelties in the present work, covering a new synthetic method of the polyporphine, fabrication of a new polyporphine/ $\mathrm{LuPc}_{2}$ heterostructure and chemosensing application of polyporphine based materials. The polyporphines are comprehensively characterized by X-ray Photoelectron Spectroscopy (XPS), optical spectroscopy, electron microscopy and electrochemical methods to elucidate their structure and thin film morphologies and properties. The electrical properties and interfacial charge transport in DLH devices are studied by Current-Voltage (I-V) measurements and Impedance Spectroscopy to unravel the nature of heterojunctions. Finally, $\mathrm{NH}_{3}$ sensing properties of DLH devices are investigated in a wide range of concentrations and at variable humidity.

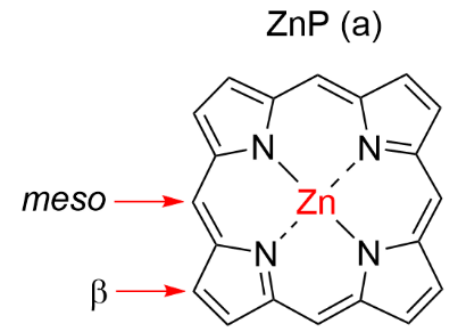

Type 1 (b)

Type 2 (c)
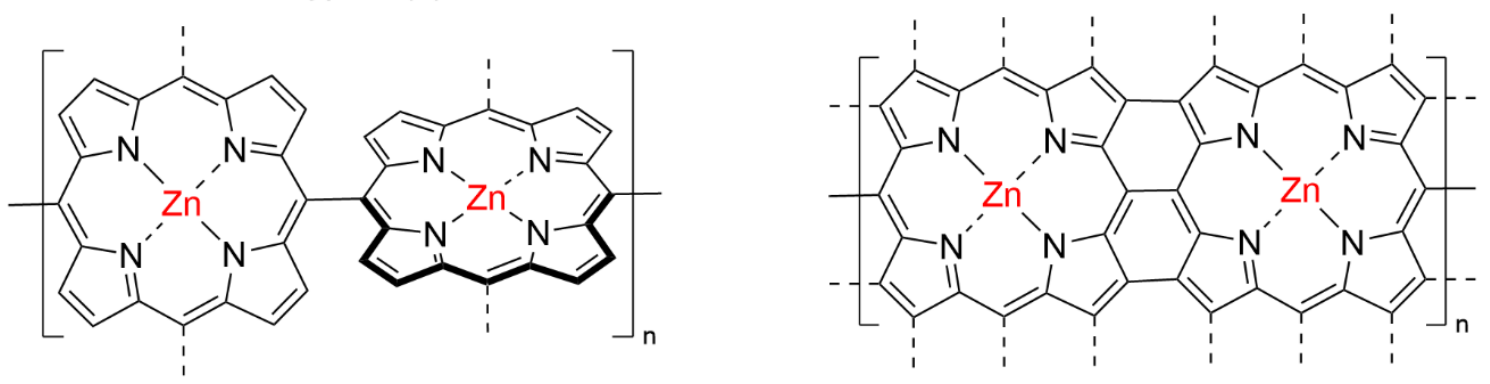

Figure 1: Molecular structure of $\mathrm{ZnP}$ monomer (a), possible molecular structures of $\mathrm{ZnP}$ polymer Type 1 (b) and ZnP polymer Type 2 (c). 


\section{Experimental}

\subsection{Reagents and Chemicals}

$\mathrm{ZnP}$ and $\mathrm{LuPc}_{2}$ were synthesized according to the published procedures [33, 38], details of which are given in supporting information. Acetonitrile (ACN) and tetrahydrofuran (THF) were procured from a local supplier and were distilled and dehydrated before use in solutions preparation. 2,6-Lutidine (2,6-dimethylpyridine; 99\%), tetra- $n$-butylammonium hexafluorophosphate $(>98 \%)\left(\mathrm{TBAPF}_{6}\right)$, potassium chloride $(\mathrm{KCl})$ and potassium hexacyanoferrate $\left(\mathrm{K}_{3}\left[\mathrm{Fe}(\mathrm{CN})_{6}\right]\right)$ were purchased from Sigma-Aldrich. $\mathrm{TBAPF}_{6}$ was dried at $80{ }^{\circ} \mathrm{C}$ prior to use. The precursors for $\mathrm{LuPc}_{2}$ and $\mathrm{ZnP}$ synthesis including 1,2-dicyanobenzene, lutetium acetate trihydrate, pyrrole, paraformaldehyde, trifluoroacetic acid, $\mathrm{POCl}_{3}, \mathrm{DMF}$, toluene, DBU, anhydrous $\mathrm{MgBr}_{2}$ and $\mathrm{Zn}(\mathrm{OAc})_{2}$ were obtained from Sigma-Aldrich.

\subsection{Electrochemical setup and electropolymerization of $\mathrm{ZnP}$}

Electrochemical experiments were performed at PGSTAT302N Autolab Metrohm workstation interfaced with Nova 2.1 software. The experiments were performed in a conventional 3-electrode cell configuration employing Pt disk (1.6 $\mathrm{mm}$ in diameter) or indium tin oxide (ITO), Pt wire and a saturated calomel electrode (SCE) as working, counter and reference electrodes, respectively. The working Pt disk was cleaned at first by polishing with alumina slurry (at first with $0.3 \mu \mathrm{m}$ followed by $0.05 \mu \mathrm{m}$ ) and then electrochemically in $0.5 \mathrm{M}$ sulfuric acid. A salt-bridge containing the same electrolyte solution as in the cell was used to house the reference electrode to avoid any leakage of $\mathrm{KCl}$ into the cell.

The electropolymerization of $\mathrm{ZnP}$ was performed in the monomer solution $(0.25-1.00$ $\mathrm{mM}$ ) prepared in an ACN/THF 50:50 v/v mixture, containing 0.1 $\mathrm{M} \mathrm{TBAPF}_{6}$ as electrolyte and $1.5 \mathrm{mM}$ 2,6-lutidine as proton acceptor [39]. Polymerization was realized in a potentiodynamic condition by cyclic voltammetry $(\mathrm{CV})$ in the range of either 0 to $0.85 \mathrm{~V}$ or 0 
to $1.20 \mathrm{~V}$, depending on the synthesis of Type- 1 or Type- 2 polymer, respectively, at the scan rate of $100 \mathrm{mV} . \mathrm{s}^{-1}$. The $\mathrm{CV}$ cycles were changed between 5 and 50 sweeps to control the quantity of deposit on the electrode surface. After the completion of the polymerization process, the electrodeposited films were washed in ACN to remove the electrolyte and unreacted monomer particles followed by drying in the ambient conditions. Similar procedures were repeated to deposit polymers films on ITO covered glass plate for different surface characterizations studies. The polymer coated electrodes were subsequently characterized by recording a $\mathrm{CV}$ in $5 \mathrm{mM} \mathrm{K}_{3}\left[\mathrm{Fe}(\mathrm{CN})_{6}\right]$ in $0.1 \mathrm{M} \mathrm{KCl}$ aqueous medium in the range of 0 to $0.40 \mathrm{~V}$ at a scan rate of $50 \mathrm{mV} . \mathrm{s}^{-1}$.

\subsection{Material characterizations}

The UV-Vis spectra of the polymers and the monomer films coated on ITO covered glass plate were recorded on a Varian's Cary® 50 spectrophotometer, using Xenon flash lamp as an excitation source in the range of $250-900 \mathrm{~nm}$. A spectrum of $\mathrm{ZnP}$ solution in ACN was also recorded in the same range using a $10 \mathrm{~mm}$ quartz cuvette for comparison with the thin films spectra. Raman spectra of the polymers and $\mathrm{ZnP}$ film were acquired by using a Renishaw inVia Raman microscope by employing a $473 \mathrm{~nm}$ laser as an excitation source.

Chemical surface analyses of the polymers and the monomer films coated on ITO covered glass substrate were conducted by XPS on a Versaprobe 5000 spectrometer (ULVAC-PHI apparatus), equipped with monochromated and focalized Al Ka X-ray source $(1486.6 \mathrm{eV})$. For each film, survey spectrum as well as high-resolution core-level windows of nitrogen $1 \mathrm{~s}$, carbon $1 \mathrm{~s}$, zinc $2 \mathrm{p}$ and oxygen $1 \mathrm{~s}$ were acquired over a spot size of $200 \mu \mathrm{m}$ and a pass energy of $187.5 \mathrm{eV}$ for spectra and $58.7 \mathrm{eV}$ for windows. The raw data were analyzed using Casa XPS software. Valence band spectra acquisition was obtained in same conditions. 
The surface morphologies of the polymers films were investigated by a scanning electron microscope (Hitachi VP-SEM SU1510) at an accelerating voltage of $30 \mathrm{kV}$, while performing the scan at different magnifications. The grain sizes of the acquired images were estimated by ImageJ software. Atomic Force Microcopy (AFM) imaging of the polymer films were performed using a Bruker Icon 2 nanoDMA equipment, operating in nanoDMA peak force mode sensitive to local mechanical properties. Silicon probes (DNP SA or ScanAsyst$\mathrm{HR}$ ) with a tip radius less than $5 \mathrm{~nm}$ were used for imaging at a peak force frequency of $2 \mathrm{kHz}$ and at amplitude in the range 50-100 nm. Nanoscope analysis software was used for particle analysis.

\subsection{Device development, characterizations and $\mathrm{NH}_{3}$ sensing}

The DLH devices were fabricated on ITO interdigitated electrodes (IDE), lithographically patterned on a $(1 \times 1) \mathrm{cm}^{2}$ glass substrate in which electrode fingers were separated by $75 \mu \mathrm{m}$. At first, electropolymerization of $\mathrm{ZnP}$ was directly performed on the IDE using the aforementioned procedure, followed by its washing in $\mathrm{ACN}$ and air-drying in ambient conditions. The polyporphine modified IDE was then transferred into a UNIVEX 250 thermal evaporator (Oerlikon, Germany) and deposition of $50 \mathrm{~nm}$ of $\mathrm{LuPc}_{2}$ was realized under secondary vacuum $\left(c a .1 .1 \times 10^{-6} \mathrm{mbar}\right)$ through thermal sublimation, maintaining the substrate temperature same as the room temperature. The sublimation temperature of $\mathrm{LuPc}_{2}$ was noted $c a .410^{\circ} \mathrm{C}$. In the vacuum chamber, another IDE and glass plate were placed next to polyporphine modified IDE to obtain $\mathrm{LuPc}_{2}$ resistor and film of $\mathrm{LuPc}_{2}$ on a glass. No post deposition heat or chemical treatments of the samples were performed.

$\mathrm{I}-\mathrm{V}$ characteristics of the fabricated polyporphines based $\mathrm{DLH}$ devices and $\mathrm{LuPc}_{2}$ resistor were studied using a Keithley electrometer in the bias voltage ranging from $-10 \mathrm{~V}$ to $+10 \mathrm{~V}$ at the steps of $0.1 \mathrm{~V}$ in ambient atmosphere. Impedance spectroscopy measurements of 
different DLH devices and $\mathrm{LuPc}_{2}$ resistor were carried out using a Solartron SI 1260 impedance analyzer integrated with SMART software. The frequency range was selected from $10 \mathrm{~Hz}$ to $10 \mathrm{MHz}$ with a fixed ac oscillation amplitude of $200 \mathrm{mV}$ and a DC bias ranging from $0 \mathrm{~V}$ to $10 \mathrm{~V}$. Experimental impedance data fitting and parameters extraction were performed using commercial software Zview (from Ametek).

The configuration of the workstation used for $\mathrm{I}-\mathrm{V}$ measurements and $\mathrm{NH}_{3}$ sensing was recently reported [40]. $\mathrm{NH}_{3}$ sensing experiments were carried out in a dynamic way through alternate exposure to different concentrations of $\mathrm{NH}_{3}$ (in the range of 10 to $90 \mathrm{ppm}$ ) for either $1 \mathrm{~min}$ or $10 \mathrm{~min}$ and recovery under clean air for either 4 or 40 minutes, at a fixed relative humidity (rh) of $40 \%$. The $\mathrm{NH}_{3}$ sensing experiments were also performed at short exposure/recovery $(1 \mathrm{~min} / 4 \mathrm{~min})$ cycles at variable rh level in the range of 10 to $70 \%$ and at each rh level, sensors were subjected to 3 different concentrations (90,60 and $30 \mathrm{ppm})$ of $\mathrm{NH}_{3}$. The rh generated in the test chamber by the inbuilt humidity generator was continuously calibrated using a commercial humidity sensor (HMT-100, Vaisala, Finland). The total flow in the sensor test chamber $\left(8 \mathrm{~cm}^{3}\right)$ was maintained at $0.5-0.55 \mathrm{NL} \mathrm{min}^{-1}$.

\section{Results and Discussions}

\subsection{Electropolymerization of $\mathrm{ZnP}$}

The electrochemical activity of $\mathrm{ZnP}$ investigated by recording a $\mathrm{CV}$ of its solution revealed two oxidation states at $0.76 \mathrm{~V}$ and $1.07 \mathrm{~V}$ (Fig. S5) similarly to the previous studies made on $\mathrm{MgP}$ [28]. They are attributed to the consecutive formation of the cation radical and dication of the porphine ring [41]. It will be shown later that oxidation at the first or second oxidation peak will lead to the formation of meso,meso-singly-linked or $\beta, \beta$-meso,meso- $\beta, \beta$ triply-fused porphine oligomers/polymers, respectively. Such electrochemical activity of ZnP 
is therefore exploited to obtain aforementioned Type 1 and Type 2 polymers to be named as pZnP-1 and pZnP-2 hereinafter. Based on the observed oxidation potentials of ZnP, multiple cycles $\mathrm{CVs}$ were recorded on bare electrode in $\mathrm{ZnP}$ solution, restricting the anodic sweep at the first oxidation wave (at $0.85 \mathrm{~V}$ ) in one case and at the second oxidation wave $(1.20 \mathrm{~V})$ in the other. The obtained voltammograms in the first case as shown in Fig. 2a depict a sharp oxidation wave peaking at $c a .0 .76 \mathrm{~V}$, that can be ascribed to fast electron transfer process generating a radical cation that is reduced at $c a .0 .70 \mathrm{~V}$ in the reversed cycle. The difference between peak potentials is $0.06 \mathrm{~V}$ close to the theoretical value for a reversible one-electron process. However, the ratio of the cathodic to anodic currents is around 0.7 , i.e. lower than expected for a pure reversible mechanism indicating that part of radical cations generated in the oxidation cycle is involved in a chemical process (EC process). Thus, it indicates that the radical cation generated at the electrode in the electrochemical step, chemically reacts with neutral $\mathrm{ZnP}$ or $\mathrm{ZnP}^{\circ+}$ in the solution, forming oligomers or polymers of $\mathrm{ZnP}$ that can be deposited on the electrode surface. The sequential increase in the oxidation peak current and broadening of the oxidation wave with increasing $\mathrm{CV}$ cycles confirm the deposition of the polymer, which was also demonstrated by the appearance of a dark gray film (inset of Fig. 1a) on the electrode surface after the experiment. 

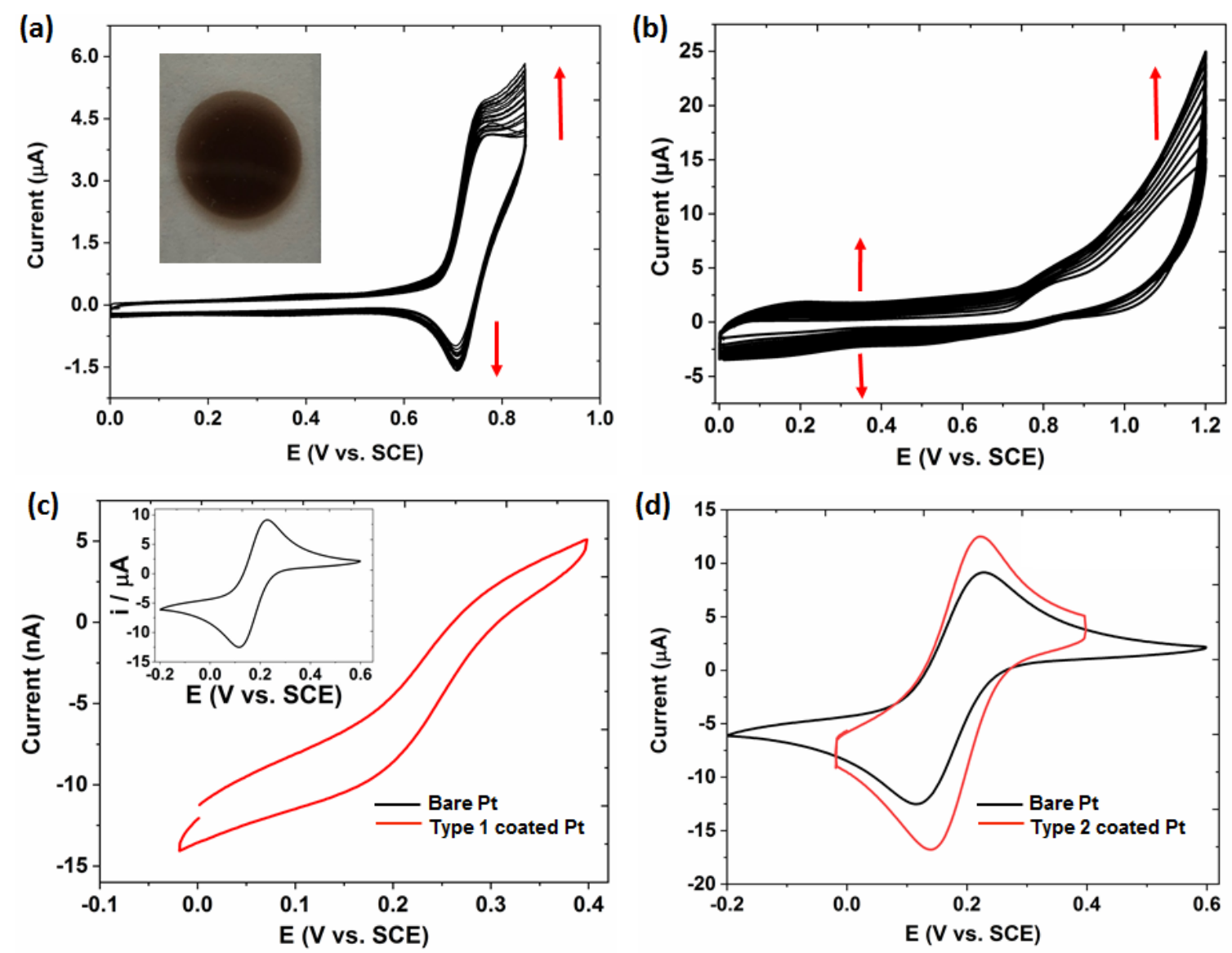

Figure 2: 20 cycles CV recorded on bare Pt electrode in $0.25 \mathrm{mM} \mathrm{ZnP}+1.5 \mathrm{mM}$ 2,6-lutidine $+0.1 \mathrm{M} \mathrm{TBAPF}_{6}$ in an ACN/THF 50:50 v/v mixture in the range of 0 to $0.85 \mathrm{~V}$ (a) and 0 to $1.2 \mathrm{~V}$ (b) at a scan rate of $100 \mathrm{mV} \mathrm{s}^{-1}$. The inset of (a) shows the optical image of coated film. The CVs of the pZnP-1 (c) and pZnP-2 (d) coated Pt electrodes, recorded in $5 \mathrm{mM}$ $\mathrm{K}_{3}\left[\mathrm{Fe}(\mathrm{CN})_{6}\right]+0.1 \mathrm{M} \mathrm{KCl}$ in the range of 0 to $0.4 \mathrm{~V}$ at the scan rate of $50 \mathrm{mV} \mathrm{s}^{-1}$.

In the other case, when potential sweep is performed until $1.20 \mathrm{~V}$, a different scenario is observed (Fig. 2b), depicting ca. 4-fold higher oxidation current and the absence of a welldefined reduction wave. This is in agreement with the formation of more ramified $\beta, \beta$ meso,meso- $\beta, \beta$-triply-fused oligomers/polymers which necessarily involves higher amount of electrons. Notably, contrary to the previous case, the capacitive current increases as a function of increasing $\mathrm{CV}$ cycles, that can be attributed to the enlargement of the surface area of the electrode with the continuous growth of a conducting polymer film. 
The electroactivity of the deposited films was investigated by recording a CV in $5 \mathrm{mM}$ $\mathrm{K}_{3}\left[\mathrm{Fe}(\mathrm{CN})_{6}\right]$ in the range of 0 to $0.4 \mathrm{~V}$ and comparing it with the one obtained at the bare electrode. A stark contrast in the voltammograms of the two films can be noticed in Fig. 2c and 2d. For the film electrodeposited at lower anodic potential sweep, the CV is characterized by a S-shape wave and $c a$. 1000 times lower current of $\mathrm{K}_{3}\left[\mathrm{Fe}(\mathrm{CN})_{6}\right]$ redox process compared to bare electrode, testifying in favor of the deposition of low conducting pZnP-1 through the meso $\mathrm{C}-\mathrm{C}$ coupling of $\mathrm{ZnP}$ monomer. On the contrary, $\mathrm{CV}$ of the film obtained at higher anodic potential sweep indicates a well-defined and sharp oxidation and reduction system and currents of $\mathrm{K}_{3}\left[\mathrm{Fe}(\mathrm{CN})_{6}\right]$ redox process higher than those obtained at the bare electrode. It testifies in favor of the deposition of conducting $\mathrm{pZnP}-2$ through ring fusion of $\mathrm{ZnP}$ monomers, which are also consistent with the large conducting area of the pZnP-2 film.

The formation of two different types of polymer films was confirmed by comparison of their UV-Visible absorption spectrum with the spectrum of the monomer. As it can be noticed in Fig. 3, the spectrum of $\mathrm{ZnP}$ monomer exhibits the characteristic intense $\mathrm{B}$ band centered at $399 \mathrm{~nm}$ and relatively weaker Q band at $529 \mathrm{~nm}$, which are similar to its solution spectra recorded in acetonitrile (Fig. S6). These absorption bands are broadened and shifted towards lower transitional energy in pZnP-1. Based on the Exciton model, such broadening and red shifts correspond to a linear chain of covalently linked monomer units, in which the transitional dipole moments in the excited state are aligned along the covalent bond between the monomer units [42], which also describe the expected geometry of pZnP-1. Moreover, splitting of B band of pZnP-1 can be also noticed, which is ascribed to Davydov splitting, arising from the strong interaction among polymeric chains in the films [43-45]. The absorption profile of pZnP-2 is however completely different in which the characteristic absorption bands are not clearly noticeable because of extended broadening. Such spectrum is typical for fused aromatic rings structures (such as graphene), arising from the dispersion of 
electronic energy levels, which decreases energy gaps of frontier orbitals. Thus, analysis of the UV-Vis absorption spectra provides an evidence of the formation of $\mathrm{pZnP}-1$ through meso-linkage and $\mathrm{pZnP}-2$ through ring fusion of $\mathrm{ZnP}$.
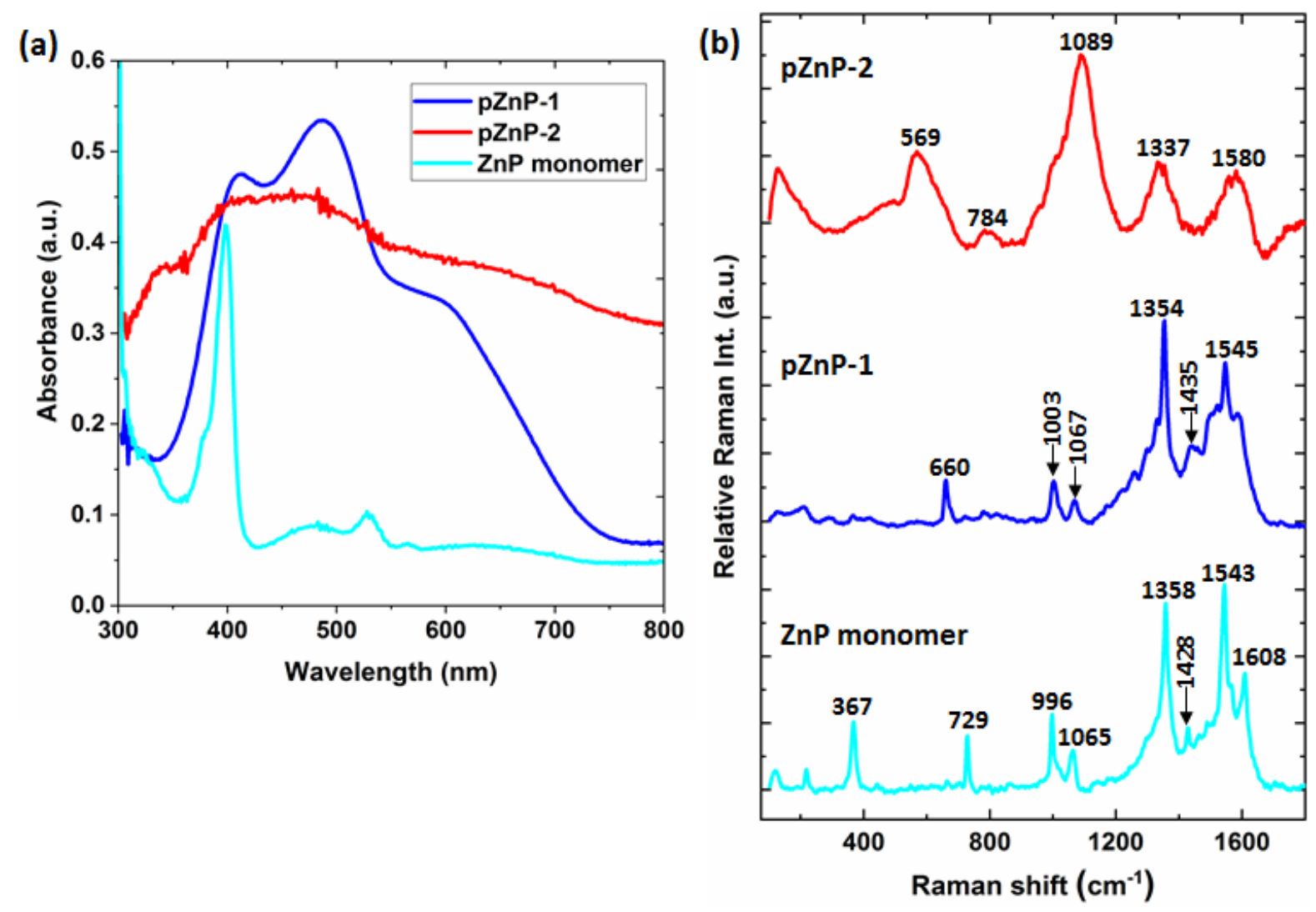

Figure 3: UV-Vis absorption spectra (a) and Raman spectra (b) of pZnP-1 and pZnP-2 and ZnP films coated on ITO substrate.

Chemical microstructure of the two polymers films were further assessed by Raman spectroscopy and a comparison of their spectra with the monomer spectrum is shown in Fig. 3b. The spectrum of $\mathrm{ZnP}$ monomer presented characteristic vibrations of metalated porphine [46] in which the peaks at $367,729,1358,1543$ and $1608 \mathrm{~cm}^{-1}$ are assigned to breathing of the macrocycle, deformation of $\mathrm{C}_{\alpha}-\mathrm{C}_{\text {meso }}-\mathrm{C}_{\alpha}$ bonds, symmetric deformation of pyrrol rings due to $\mathrm{C}_{\beta}-\mathrm{C}_{\beta}$ stretching, bending of $\mathrm{C}_{\alpha}-\mathrm{N}-\mathrm{C}_{\alpha}$ and $\mathrm{C}_{\beta}-\mathrm{C}_{\beta}$ bonds and rocking of the $\mathrm{H}$ on the $\mathrm{C}_{\alpha}-\mathrm{C}_{\text {meso }}{ }^{-}$ $\mathrm{C}_{\alpha}$ bonds , respectively. The vibrational assignments of all the peaks are given in Table S1. 
The spectrum of pZnP-1 preserved some of the principle Raman active bands of porphine such as those at 1003, 1067, 1354 and $1545 \mathrm{~cm}^{-1}$ are noticed. However, bands sensitive to vibrations around meso-carbons either disappeared or diminished in intensity (at 729, 1608 $\mathrm{cm}^{-1}$ ). It indicates that vibrational degree of freedom around the meso-carbon is diminished, which also provides an evidence of formation of pZnP-1 through meso-meso covalent linkage. The spectrum of pZnP-2 displays different features in which principal Raman peaks of porphine merged with less intense peaks, with a marked broadening. The disappearance of many Raman active bands is consistent with the limitations in vibrational degree of freedom in a fused pZnP-2 structure. Moreover, asymmetric broadening of the peaks indicates an amorphous disordered structure [47]. Such vibrational peak broadening were previously noted in the IR spectrum of pMgP-2 [48].

\subsection{Elemental and Microstructural characterizations of polyporphines}

The evidence of the polymers formation was further provided by the XPS analyses of the electrodeposited films and ZnP monomer on ITO substrate. The elemental composition of films were identified by survey XPS spectra (Fig. 4a), presenting characteristic XPS peaks of carbon, nitrogen and zinc at ca. 284, 398 and $1021 \mathrm{eV}$, respectively, in the electrodeposited films and in the $\mathrm{ZnP}$ film. Moreover, the elemental ratio of nitrogen and zinc as deduced from Table S2 is 3.2 and 3.8 for $\mathrm{pZnP}-1$ and $\mathrm{pZnP}-2$, respectively, which are near the theoretical value of 4 in $\mathrm{ZnP}$ monomer. The presence of the constituent elements of $\mathrm{ZnP}$ and conservation of $\mathrm{N} / \mathrm{Zn}$ ratio clearly indicate the formation of polymeric structure in the electrodeposited films. The intense peak at $532 \mathrm{eV}$ in the polymers as well as in the monomer spectra is assigned to adventitious oxygen, which can be attributed to the adsorption of $\mathrm{H}_{2} \mathrm{O}$ or hydroxides on the surface of the film [49]. To gain in depth information about the nature of chemical bonds and oxidation states of each element, high-resolution core level XPS spectra 
were recorded for each material. The N1s spectra of the both electrodeposited films (Fig. 4b and 4c) revealed the principle peak at $398 \mathrm{eV}$, corresponding to the identical metal-nitrogen bonds in $\mathrm{ZnP}$ [50]. The appearance of a broad shoulder, deconvoluted at $c a .400 .5 \mathrm{eV}$ can be a shake-up satellite, which is commonly observed in MPor because of photoionization during XPS experiments [51]. Nonetheless, the contribution from a pyrrolic nitrogen of a free base porphine can not be ruled out [52], which appears at $400 \mathrm{eV}$ and points towards a possible demetalation of $\mathrm{ZnP}$ macrocycle. Such demetalation is more evident in $\mathrm{pZnP}-2$, depicting relatively sharper peak at $c a .400 \mathrm{eV}$ in its $\mathrm{N} 1 \mathrm{~s}$ spectrum, which indicates the presence of larger proportion of pyrrolic nitrogen. The origin of this demetalation can be attributed to oxidative environment of the electropolymerization in which loss of protons because of C-C couplings of $\mathrm{ZnP}$ monomers creates high local acidity, removing some of the $\mathrm{Zn}$ from the central cavity. The higher demetalation in $\mathrm{pZnP}-2$ is also in agreement with the larger proton loss (up to $8 \beta$-pyrrolic protons) in the ring fusion of $\mathrm{ZnP}$. Polymeric films contain identical carbon skeleton in each repeat unit to that of the monomer, exhibited by the similar $\mathrm{C} 1 \mathrm{~s}$ spectra of the polymers and $\mathrm{ZnP}$ (Fig. S7), showing a common peak at ca. $284 \mathrm{eV}$. The degradation of porphine macrocycle in the polymeric structures is also ruled out because of the absence of any signature of C-O (286-289 eV) and N-O (403-407) bonds in C1s and N1s spectra, respectively. The polymeric films also revealed symmetric $\mathrm{Zn}_{\mathrm{P} 3 / 2}$ spectra, depicting a well-defined peak at $c a .1021 .5 \mathrm{eV}$ that can be assigned to coordinated $\mathrm{Zn}$ (II) ion, indicative of a $\mathrm{Zn}$ centered porphine macrocycle [53]. 

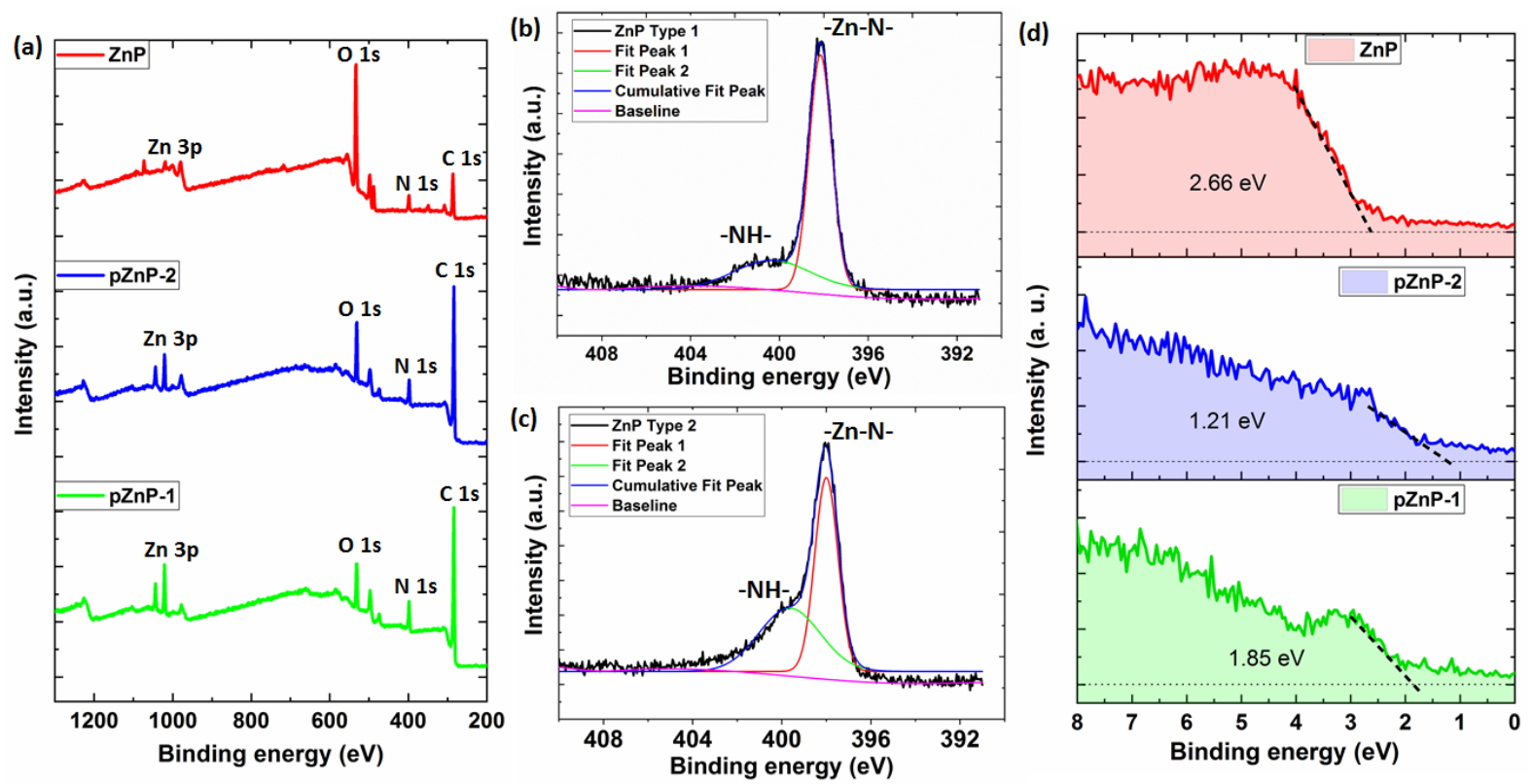

Figure 4: Survey XPS spectra of monomer, pZnP-1 and pZnP-2 coated on ITO substrate (a), high resolution $\mathrm{N} 1 \mathrm{~s}$ core-level spectra of $\mathrm{pZnP}-1$ (b) and pZnP-2 (c) and valence band spectra of monomer, pZnP-1 and pZnP-2 (d).

The electronic properties of the electrodeposited polymer films were assessed by analyzing their XPS valence band spectra and that of $\mathrm{ZnP}$ monomer. The Valence Band Maximum (VBM) of the polymers spectra as indicated in Fig. 4d displayed a shift towards the lower binding energy as compared to $\mathrm{ZnP}$ monomer. It indicates that Highest Occupied Molecular Orbital (HOMO) level of the polymers moves upward closer to the Lowest Occupied Molecular Orbital (LUMO) level, narrowing the band gap after the polymerizations [26]. Moreover, the decrease in $\mathrm{VBM}$ is higher in $\mathrm{pZnP}-2$ compared to $\mathrm{pZnP}-1$, implying the larger upward shifts of the HOMO level. This can be attributed to the extension of $\pi$ conjugation in pZnP-2, decreasing the band gap and increasing the conductivity of the film [54]. Based on the VBM and optical band gap estimated from UV-Vis spectra in Fig. 3a, HOMO and LUMO energies were estimated and are plotted in Fig. S8. Therefore, the electronic properties of the polymers film coupled with their chemical structure analysis validates our assumption of the formation of polymer films with different geometries. 
The surface of both polymers film presented similar morphologies as exhibited in their SEM micrographs (Fig. 5a and 5b). The surfaces are homogeneous and composed of densely packed polymeric grains of globular shape. These grains are relatively smaller in $\mathrm{pZnP}-1$ compared to those found in $\mathrm{pZnP}-2$. Moreover, these surfaces also display a few $\mu \mathrm{m}$-sized aggregates, which are not $\mathrm{TBAPF}_{6}$ electrolyte particles as confirmed by the XPS measurements, rather they represent the polyporphine grains. The origin of these aggregates are attributed to the presence of some oligomers in the solution, which are not immobilized on the electrode surface just after the electropolymerization but stay within the diffusion layer during the repetitive $\mathrm{CV}$ cycling. They can be attached to the propagating chain of the polymers and act like a larger nucleation center, attracting larger mass transport around it and thus forming aggregates.

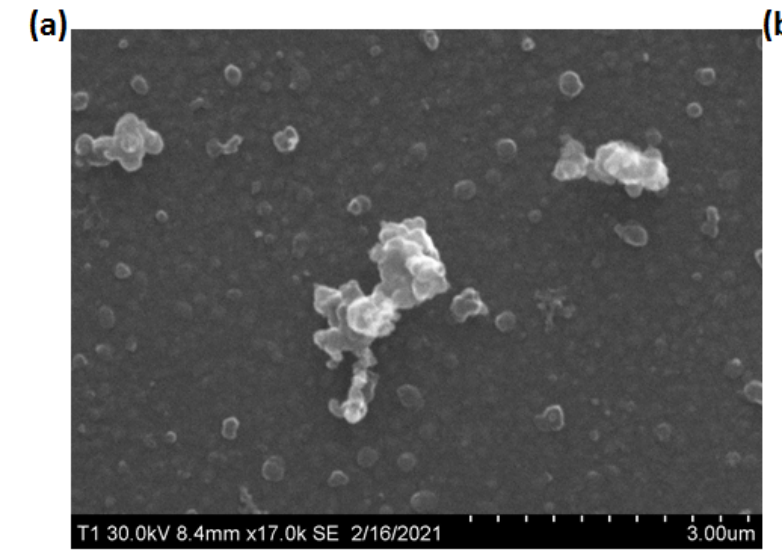

$$
\text { (c) }
$$
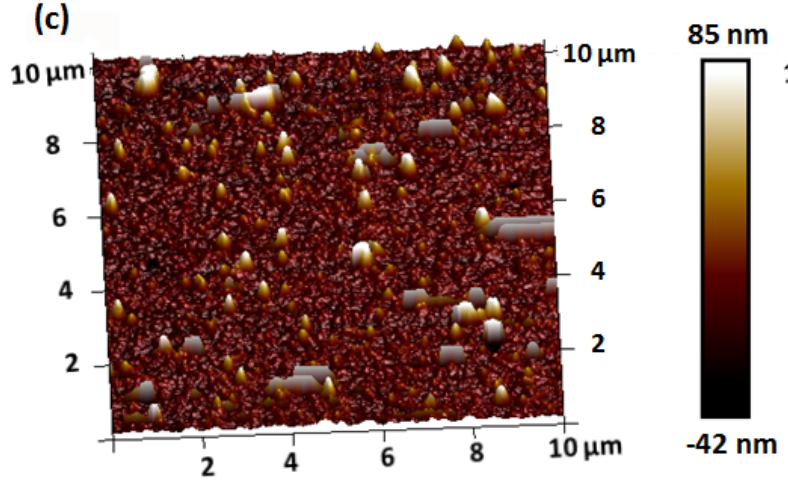

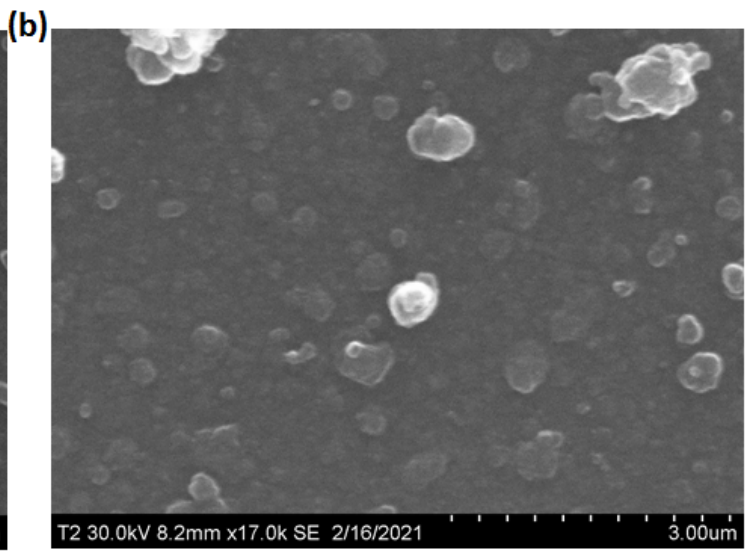

(d)

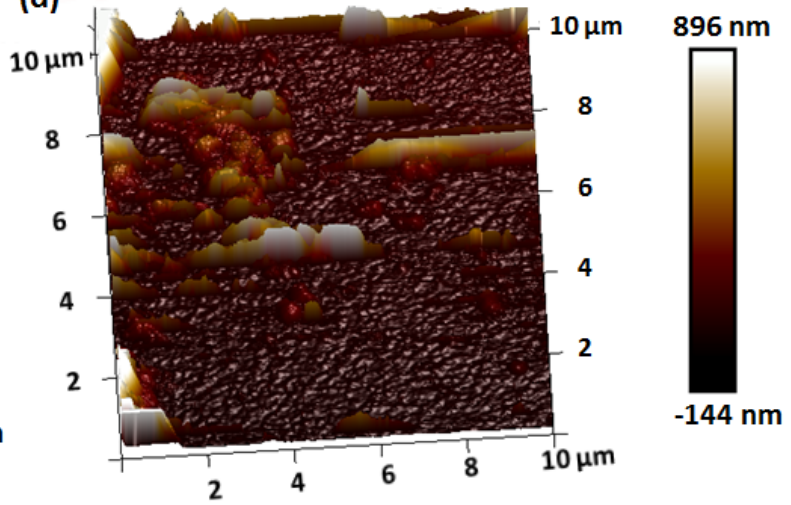

Figure 5: SEM and AFM images of pZnP-1 (a and c) and pZnP-2 (b and d) films coated on ITO substrate. 
AFM imaging of the polymers film further complemented the morphologies studies and provided important topographical information of the surfaces. The two surfaces revealed a dense packing of polymer grains but with distinct topographical features (Fig. 5c and 5d) such that surface height variations of pZnP-2 are ca. 10 fold higher than pZnP-1. The RMS roughness was estimated ca. $25 \mathrm{~nm}$ and $197 \mathrm{~nm}$ for pZnP-1 and pZnP-2, respectively, confirming a coarse surface of the latter. For the reference, the roughness of the ITO substrate was also measured (Fig. S9), which was found to be much lower than the polymer surfaces with a RMS value of ca. $6 \mathrm{~nm}$. Notably, the surface of pZnP-1 has a more homogeneous distribution of similar sized polymer aggregates. On the contrary, aggregates in pZnP-2 film differ a lot in their dimensions and have a non-homogeneous distribution. For instance, it is evident in the Fig. 5d that majority of bigger grains are agglomerated in the top left part of the image while remaining parts appear smooth (on the RMS length scale). The surface height analysis of the selected aggregates in the two polymers films was also performed and is shown in Fig. S10, which exhibits a ca. $500 \mathrm{~nm}$ wide and $90 \mathrm{~nm}$ high grain of pZnP-1 and a ca. $2.5 \mu \mathrm{m}$ wide and $300 \mathrm{~nm}$ high grain of $\mathrm{pZnP}-2$.

\subsection{Charge transport at the $\mathrm{pZnP} / \mathrm{LuPc}_{2}$ heterojunction}

For the heterojunction device development, $\mathrm{ZnP}$ was directly electropolymerized on the interdigitated fingers of ITO electrodes patterned on glass substrate (Fig. 6a). It can be noticed that coating of the polymer occurs only at the interdigitated fingers, leaving the spacing between them unoccupied. Such coating on the ITO electrodes makes them suitable for DLH device fabrication because another organic semiconductor can be coated over it, filling the space around pZnP modified ITO fingers and forming two symmetric organic- 
organic lateral junction (Fig. 6b). This configuration was achieved by depositing a layer of $\mathrm{LuPc}_{2}$ over the $\mathrm{pZnP}$ modified ITO.

(a)

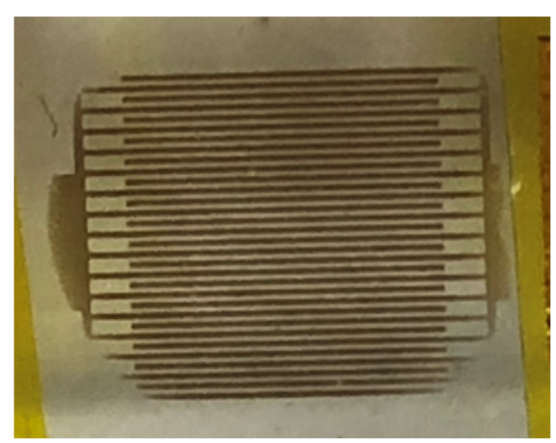

(c)

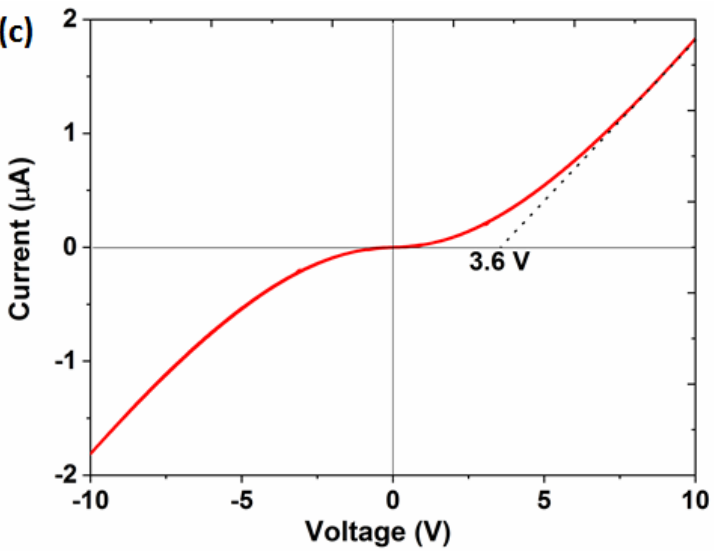

(b)

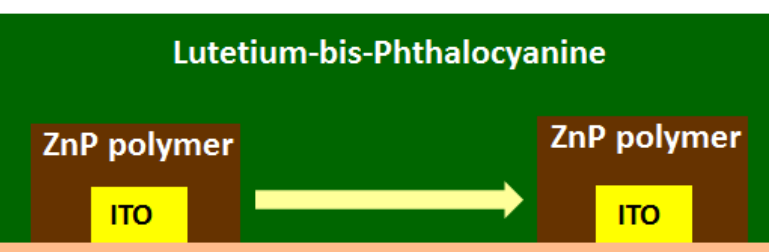

Glass substrate

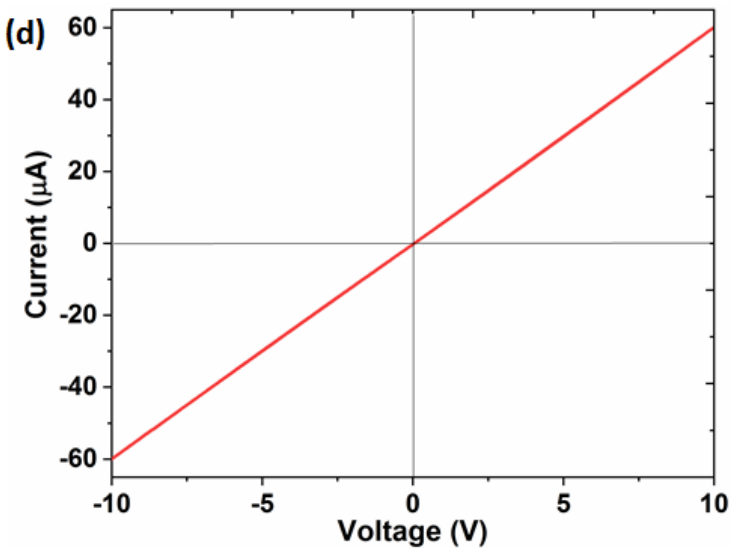

Figure 6: Optical image of the electropolymerized pZnP-1 on IDE of ITO on a glass support (a) and scheme of the DLH device based on $\mathrm{ZnP}$ polyporphine/LuPc $\mathrm{C}_{2}$ heterojunction (b). I-V curves of $\mathrm{pZnP}-1 / \mathrm{LuPc}_{2}(\mathrm{c})$ and $\mathrm{pZnP}-2 / \mathrm{LuPc}_{2}(\mathrm{~d}) \mathrm{DLH}$ device recorded in the bias voltage range of $-10 \mathrm{~V}$ to $+10 \mathrm{~V}$.

The I-V characteristics of the two DLH devices presented symmetric but different profiles depending on the type of sublayer between $\mathrm{pZnP}-1$ and $\mathrm{pZnP}-2$. As bias voltage is swept from -10 to $+10 \mathrm{~V}$, the type-1 polymer based device (Fig. 6c) revealed a non-linear variation of current, typical of a space charge limited regime of charge transport contrary to type-2 based device, displaying a linear variation of current, typical of an ohmic transport. Moreover, the magnitude of current at $+10 \mathrm{~V}$ is $c a .33$ times lower in pZnP-1 than in pZnP-2 based device, highlighting the high resistance of the former, which also corroborates the 
conclusions of Fig. 2c and 2d. The non-linearity in the I-V curve of an organic heterojunction device emanates from the interfacial accumulation of $\mathrm{e}^{-}$and $\mathrm{h}^{+}$because of the workfunction difference of the constituent materials in the heterostructure and the huge variation in the bulk and interfacial mobility of charges. For the pZnP-1 based DLH device, the sublayer has low conductivity, making it difficult for the injected charges from the electrode to arrive at the relatively more conducting interface region at low bias, which results in small current. However, at higher bias, the injected charges from the electrode have sufficient energy to overcome the high resistance of the sublayer bulk and arrive at the interface readily, exhibiting higher current of the device. The apparent energy barrier $\left(\mathrm{U}_{\mathrm{th}}\right)$ of the interfacial charge transport is obtained by drawing a tangent to the I-V curve at higher bias on abscissa, which is obtained as $3.6 \mathrm{~V}$ for $\mathrm{pZnP}-1 / \mathrm{LuPc}_{2}$ device. On the contrary, the appearance of a linear I-V curve in pZnP-2 based DLH device indicates high mobility of the charges present in the bulk of the sublayer as well as negligible difference in the bulk and interfacial mobility of charges. This is attributed to the extended $\pi$-conjugation in pZnP-2, making the electronic transport in the sublayer facile and similar to the high conducting $\mathrm{LuPc}_{2}$ (Fig. S11).

The charge transport in DLH devices was further investigated by impedance spectroscopy in a wide frequency range $(10 \mathrm{~Hz}$ to $10 \mathrm{kHz})$ at different $\mathrm{DC}$ bias between 0 and $10 \mathrm{~V}$. The Nyquist plots of the measurements exhibited distinct features depending on the type of polyporphine in the DLH devices. The device based on pZnP-1 displayed two depressed semicircles (Fig.7a) in which the one at high frequency (HF) remains constant, while the one at low frequency (LF) gets smaller as a function of increasing DC bias. Clearly, the former represents the bulk transport in the device, which remains independent of the bias and the latter corresponds to the interfacial transport, which becomes easier with increasing bias [55]. On the contrary, the Nyquist plots of the DLH device based on pZnP-2 show only one semicircle (Fig. 7b) in the whole frequency range, which remains of the same size at 
different bias, identical to $\mathrm{LuPc}_{2}$ resistor (Fig. 7c), indicating the prevalence of only bulk transport and the absence of any interface effect.

(a)

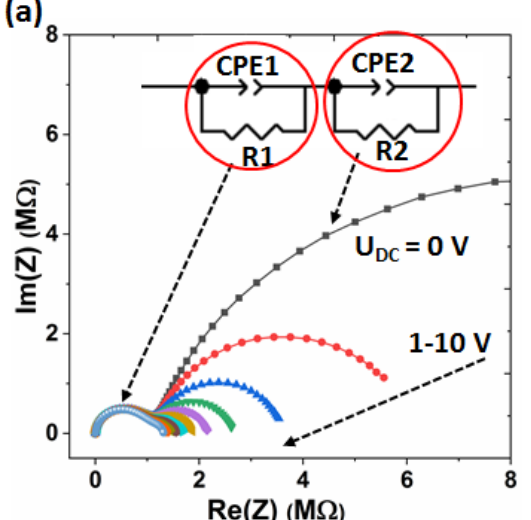

(d)

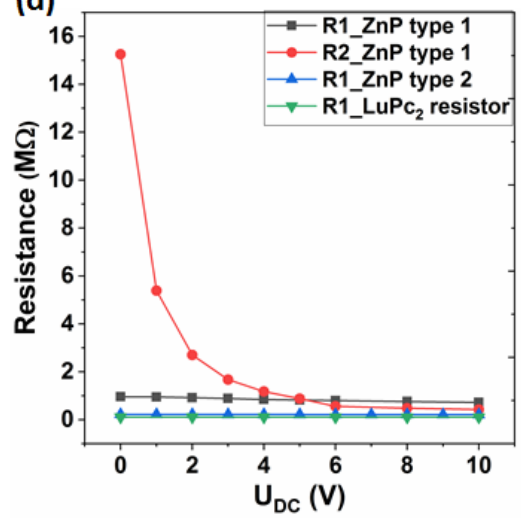

(b)

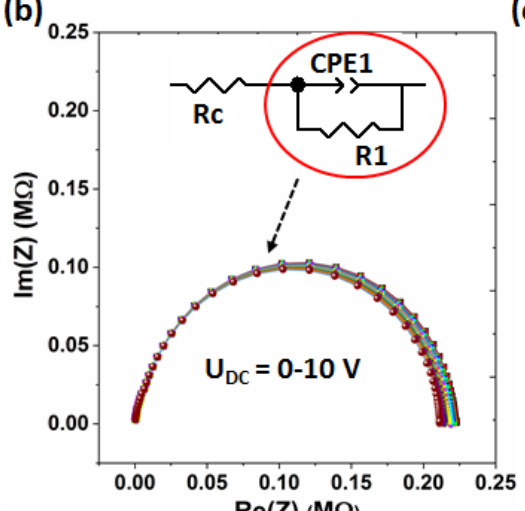

(e)

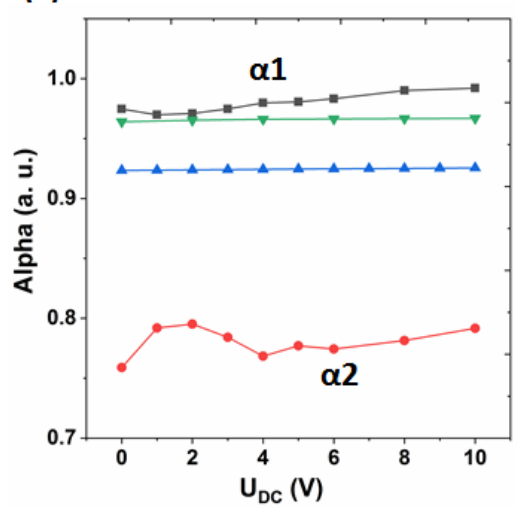

(c)

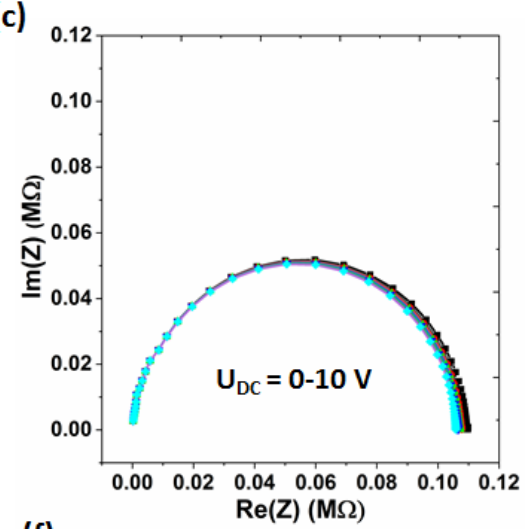

(f)

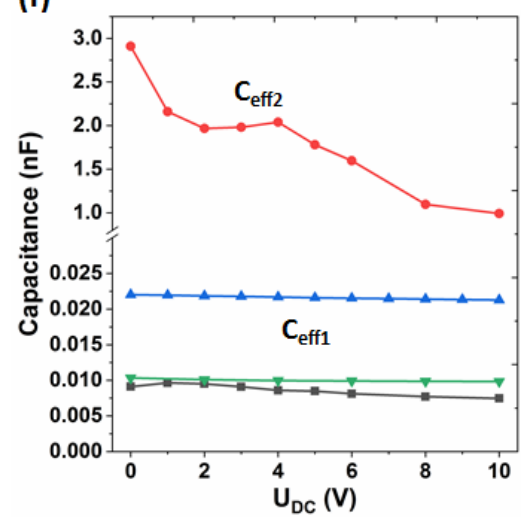

Figure 7: Experimental and fitted Nyquist plots of pZnP-1/LuPc $\mathrm{L}_{2} \mathrm{DLH}$, (a) $\mathrm{pZnP}-2 / \mathrm{LuPc}_{2}$ DLH (b) and $\mathrm{LuPc}_{2}$ resistor (c) recorded in the range of 10 to $10 \mathrm{MHz}$ at different DC bias (0 to $10 \mathrm{~V}$ ) and at a fixed $\mathrm{AC}$ bias of $0.2 \mathrm{~V}$. The insets of (a) and (b) indicate the equivalent circuits used to fit the experimental curves and Nyquist curves in (c) fit with the same circuit as used in (b). The variations of the equivalent circuit parameters, resistance (d), alpha (e) and effective capacitance (f) with applied bias of the different devices. The curves in (e) and (f) follow the same color codes as used in (d).

The Nyquist plots were modelled by Constant Phase Element (CPE) based equivalent circuits, owing to the distributed microstructural properties of the heterostructure [56], which is an imperfect capacitor in which its impedance $\mathrm{Z}_{\mathrm{CPE}}$ is given by the equation (1). Here $\mathrm{Q}_{\mathrm{i}}$ refers to the non-ideal capacitance, $\omega$ is related with the frequency $(2 \pi f)$ and $\alpha$ is a coefficient 
changing between 0 and 1 such that its upper and lower limits correspond to an ideal capacitor and an ideal resistor, respectively.

$Z_{C P E_{i}}=\frac{1}{Q_{i} \times(j \omega)^{\alpha_{i}}}$

The Nyquist plots of pZnP-1 based DLH device were fitted with an equivalent circuit having two Ri-CPEi elements arranged in series (Inset of Fig. 7a) in which the semicircles at HF are described by bulk resistance R1 and CPE1, while those at LF are explained by interfacial resistance R2 and CPE2. On the other hand, Nyquist plots of pZnP-2 based DLH and of $\mathrm{LuPc}_{2}$ resistor were fitted with one R1-CPE1 element, corresponding to the bulk resistance $\mathrm{R} 1$ and CPE1. Through the fitting, different circuit parameters such as resistance (R), $\alpha$ and effective capacitance $\left(\mathrm{C}_{\text {eff }}\right.$; defined by equation 2$)$ were determined and have been used to describe the electrical nature of the devices [40].

$C_{e f f i}=Q_{i}^{\frac{1}{\alpha_{i}}} \cdot R_{i}^{\frac{1}{\alpha_{i}}-1}$

The variation of bulk and interfacial charge transfer resistances with DC bias are shown for different devices in Fig. 7d, exhibiting decrease in $\mathrm{R} 2$ of pZnP-1 based DLH from ca. $15 \mathrm{M} \Omega$ to ca. $1 \mathrm{M} \Omega$, while almost no change in $\mathrm{R} 1$ of all devices as bias changes from 0 to $10 \mathrm{~V}$. Notably, most of decrease in R2 takes place until $4 \mathrm{~V}$, following that it attains a steady state regime. It indicates that injected charges encounter an energy barrier of approximately $4 \mathrm{~V}$ to arrive at more conducting interface region, which is also in agreement with the $\mathrm{U}_{\text {th }}$ obtained from the I-V curve of $\mathrm{pZnP}-1 / \mathrm{LuPc}_{2} \mathrm{DLH}$ device. On the other hand, charge transfer resistances in pZnP-2 based DLH device is very low (ca. $2 \mathrm{k} \Omega$ ), similar to $\mathrm{LuPc}_{2}$ resistor, which remain constant at different bias, typical for a bulk transport. It is consistent with higher current in the I-V curve of the device and is attributed to extended $\pi$-conjugation in pZnP-2, enabling easier conduction of charges. On the contrary, $\mathrm{pZnP}-1 / \mathrm{LuPc}_{2} \mathrm{DLH}$ device 
shows more resistive bulk transport, owing to restriction of $\pi$-conjugation in the polymer chain. The $\alpha 1$ of different DLH devices and the resistor are close to 1 at different bias, indicating the behavior of R-CPE elements of the bulk as an ideal capacitor. Therefore, distribution in the CPE are very low, owing to the homogeneous microstructure of the bulk. However, $\alpha 2$ of pZnP-1 based DLH is ca. 0.75 and exhibits some variations $( \pm 0.05)$ as bias increases. It indicates dispersion in the CPE, which is attributed to enhancement in surface heterogeneity at the interface of $\mathrm{pZnP}-1 / \mathrm{LuPc}_{2}$ heterojunction $[57,58]$. To assess the strong interface effect on the charge transport in $\mathrm{pZnP}-1 / \mathrm{LuPc}_{2}$ device, the effective capacitances $\left(\mathrm{C}_{\mathrm{eff} 1} \& \mathrm{C}_{\mathrm{eff} 2}\right)$ were analyzed. As noticed in Fig. $7 \mathrm{f}, \mathrm{C}_{\mathrm{eff} 2}$ associated with opposite charges accumulation at the pZnP-1 and $\mathrm{LuPc}_{2}$ interface are between 1 and $3 \mathrm{nF}$, which are 3 -order of magnitude higher than the bulk capacitance $\left(\mathrm{C}_{\text {eff1 }}\right)$, confirming the accumulation of $\mathrm{e}^{-}$and $\mathrm{h}^{+}$ at the interface of the heterojunction. Since, capacitance is inversely proportional to the thickness, it corroborates with the fact that organic heterojunction interface is much thinner than the bulk [59]. On the contrary, $\mathrm{pZnP}-2 / \mathrm{LuPc}_{2}$ device exhibited very low capacitance in $\mathrm{pF}$, which confirms the absence of significant interface effect in the device.

\section{4. $\mathrm{NH}_{3}$ sensing properties of $\mathrm{pZnP} / \mathrm{LuPc}_{2}$ heterojunction devices}

The influence of different polyporphines in the DLH devices on their $\mathrm{NH}_{3}$ sensing behavior was investigated by applying alternate exposure to $90 \mathrm{ppm}$ of $\mathrm{NH}_{3}$ and recovery under clean air for 10 and 40 minutes, respectively, at fixed relative humidity (rh) of $40 \%$. As depicted in Fig. 8a and 8b, the devices current decreases upon exposure to electron donating $\mathrm{NH}_{3}$ and recovers during passage of clean air, highlighting the p-type nature of both devices. However, the reversibility and baseline stability of the responses greatly varied depending on pZnP-1 and pZnP-2 as sublayer in the devices, such that the former displays highly reversible 
response and a stable baseline, contrary to the irreversible response and continuous baseline drift in the latter. The irreversible response of pZnP-2 based sensor is attributed to a possible diffusion of $\mathrm{NH}_{3}$ within the sublayer volume, which has a larger area compared to pZnP-1 as noticed in the higher capacitive current in Fig. 2b. The RR of these response curves, derived from equation (Eq. S1) were obtained ca. $47 \%$ and ca. $7.8 \%$ for pZnP-1 and pZnP-2 based devices, respectively. It highlights the advantages of using pZnP-1 in the heterostructure and inducing significant interface effects to obtain a sensitive, reversible and stable sensor for $\mathrm{NH}_{3}$. Accordingly, in depth investigation of its $\mathrm{NH}_{3}$ sensing properties was performed.
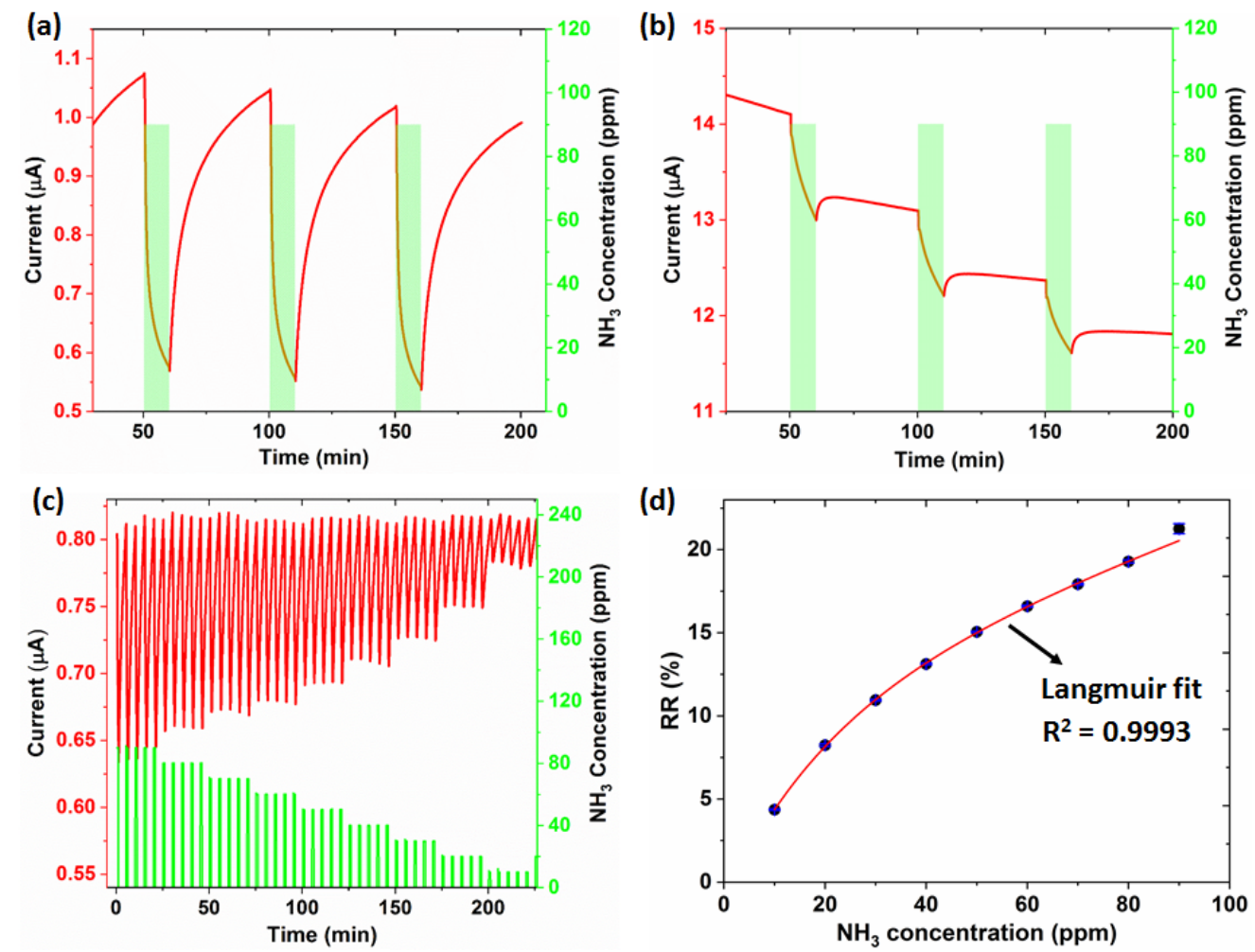

Figure 8: Response of $\mathrm{pZnP}-1 / \mathrm{LuPc}_{2}$ (a) and $\mathrm{pZnP}-2 / \mathrm{LuPc}_{2}$ (b) $\mathrm{DLH}$ devices towards repetitive exposure to $90 \mathrm{ppm}$ of $\mathrm{NH}_{3}$ for 10 min and recovery under clean air for 40 minutes, at $\mathrm{rh} 40 \%$ and at an applied bias of $3 \mathrm{~V}$. The response of $\mathrm{pZnP}-1 / \mathrm{LuPc}_{2}$ sensor towards different concentrations of $\mathrm{NH}_{3}$ in the range of 10-90 ppm for short exposure/recovery periods (1 $\mathrm{min} / 4 \mathrm{~min}$ ) at fixed $\mathrm{rh}$ of $40 \%$ (c). The calibration curve obtained from (c), depicting variation of $\mathrm{RR}$ with $\mathrm{NH}_{3}$ concentration (d). 
$\mathrm{NH}_{3}$ sensing performance of $\mathrm{pZnP}-1 / \mathrm{LuPc}_{2}$ device studied in the range of 10 to 90 ppm, employing short exposure and recovery steps of $1 \mathrm{~min}$ and $4 \mathrm{~min}$, respectively, are shown in Fig. 8c. For each concentration step, 5 exposure/recovery cycles were performed to evaluate repeatability of the sensor. Notably, responses are very stable and repeatable exhibited by a constant baseline and similar variations in current in each exposure/recovery cycle at a given $\mathrm{NH}_{3}$ concentration. Moreover, the change in device current at each new concentration is distinguishable and increases in magnitude with increasing $\mathrm{NH}_{3}$ concentration. A calibration curve (Fig. 8d), depicting the variation of RR as a function of $\mathrm{NH}_{3}$ concentration revealed a non-linear profile. Such non-linear behavior of the calibration curve resembles to Langmuir isotherm [60], indicating limited availability of adsorption sites on the sensor surface, because of that competition among $\mathrm{NH}_{3}$ molecules takes place to occupy an adsorption site at higher concentration, leading to saturation of the response. To validate our assumption of the adsorption mechanism, the calibration curve was fitted with Langmuir equation, which fits accurately and RR of the sensor at a given concentration $\left(\mathrm{C}_{\mathrm{NH} 3}\right)$ can be given by equation (3). In this equation, $A$ represents the maximum RR value that sensor can display when all available active sites are occupied. $K$ refers to affinity constant of adsorption that corresponds to the ratio of the adsorption and desorption rate constants.

$$
R R=A \frac{K c_{N H 3}}{1+K c_{N H 3}}
$$

The fitting parameters $A$ and $K$ were obtained as $c a .33$ and 0.0138. It indicates that sensor can display maximum RR up to $33 \%$. The similar sensing studies performed on $\mathrm{pZnP}-2 / \mathrm{LuPc}_{2}$ device revealed a highly unstable response exhibited by continuous baseline drift (Fig. S12). The RR of the sensors at $10 \mathrm{ppm}$ and $90 \mathrm{ppm}$ of $\mathrm{NH}_{3}$ were estimated as $1.14 \%$ and $1.42 \%$, 
indicating its low sensitivity and incapability to produce discriminated response at different $\mathrm{NH}_{3}$ concentrations.

For practical application of a $\mathrm{NH}_{3}$ sensor, humidity is a potential interferent, therefore the response of $\mathrm{pZnP}-1 / \mathrm{LuPc}_{2}$ sensors was investigated at different rh in the range of 10 to $70 \%$ by changing the $\mathrm{NH}_{3}$ concentration between 30 to $90 \mathrm{ppm}$ through short exposure/recovery cycles $(1 \mathrm{~min} / 4 \mathrm{~min})$. The device exhibited a repeatable variation of current at each concentration of $\mathrm{NH}_{3}$ at a fixed rh level, but experiences larger variation with increasing rh (Fig. S13). This can be attributed to electron donating nature of $\mathrm{H}_{2} \mathrm{O}$ like $\mathrm{NH}_{3}$, resulting in higher current decrease. The $\mathrm{RR}$ of the sensor at $30 \mathrm{ppm}$ of $\mathrm{NH}_{3}$ changes from $9.8 \%$ to $11.3 \%$ as rh is changed from 30 to $70 \%$, whereas the RR at $90 \mathrm{ppm}$ of $\mathrm{NH}_{3}$ changes from $17.9 \%$ to $23.6 \%$ in the same range of rh variations. Therefore, despite some interferences of $\mathrm{rh}$ in $\mathrm{NH}_{3}$ detection, the sensor signals can be discriminated at different concentrations. Moreover, RR at each concentration are repeatable at each fixed level of rh. However, more significant decrease in the RR at each concentration is noticed in a very dry environment (rh 10\%), which is rarely found in the practical application of such sensors.

\section{Conclusion}

We have demonstrated a new and direct electrochemical synthetic approach to obtain different types of zinc(II) polyporphines and validated their high potentiality in organic heterostructures development for gas sensors application. Two different types of polyporphines $\mathrm{pZnP}-1$ and $\mathrm{pZnP}-2$, differing in their geometrical orientation, conductivity and surface area of the film are synthesized by electropolymerization of $\mathrm{ZnP}$ monomer through $\mathrm{CV}$ cycling. The range of the anodic sweep is the key factor, determining the nature of polymers generated at the electrode surface such that at less positive potential, pZnP-1 
polymer is produced through meso-linkage of the monomer units, while at higher potential pZnP-2 polymer is produced through meso and $\beta$ linkages, causing fusion of the monomer units. The film of pZnP-2 exhibited much higher conductivity than pZnP-1, which is attributed to the extension of $\pi$-conjugation in the polymer film also confirmed by its very wide and almost assimilated Q and B absorption bands in UV-Vis spectrum. The structure and chemical purity of the two polyporphines are further validated by XPS studies, showing the expected oxidation states of the constituent elements and elemental composition similar to that of monomer. In particular, XPS valence band spectra explicitly confirmed the formation of two different types of polymers and larger upward shift of HOMO of $\mathrm{pZnP}-2$ because of $\pi$ conjugation. Association of these polyporphines in organic heterostructures with $\mathrm{LuPc}_{2}$ revealed distinct electrical properties and charge transfer regimes. The DLH device based on pZnP-1 exhibited non-linear I-V characteristics with a high interfacial energy barrier contrary to a linear I-V correlation and negligible interface effect in $\mathrm{pZnP}-2$ based $\mathrm{DLH}$ device. The predominance of interfacial charge transport in $\mathrm{pZnP}-1$ based $\mathrm{DLH}$ is further confirmed by impedance spectroscopy. The strong interfacial charge transport in $\mathrm{pZnP}-1 / \mathrm{LuPc}_{2}$ device also resulted in its higher sensitivity, reversibility and stability towards $\mathrm{NH}_{3}$ detection. This device showed discriminated response at different concentrations of $\mathrm{NH}_{3}$ in the range of 10 to 90 ppm, making it suitable for deployment in real occupation spaces, as it can detect $\mathrm{NH}_{3}$ levels below the maximum exposure limit ( $25 \mathrm{ppm}$ continuously for $8 \mathrm{~h}$ ) mandated by occupation safety agencies, such as Occupation Safety of Health Administration.

\section{Acknowledgment}

The authors are thankful for receiving generous funding from Université de Bourgogne and European Union through PO FEDER-FSE Bourgogne 2019/2022 (via 
CoMICS program), Agence Nationale de la Recherche (ANR) through the project OUTSMART ANR-2015-CE39-0004-03 and Conseil Régional de Bourgogne and European Union through the CPER program. A.K. acknowledges Université de Bourgogne for a postdoctoral fellowship through the BQR program. C. H. D. thanks the French “'Investissement d'Avenir” program, project ISITE-BFC (contract ANR-15-IDEX-03) for funding. Authors thank Anthony Perronnet (from SATT-SAYENS) for performing SEM measurements.

\section{References}

[1] H. Wang, D. Yan, Organic heterostructures in organic field-effect transistors, NPG Asia Mater. 2 (2010) 69-78. https://doi.org/10.1038/asiamat.2010.44.

[2] V. Rani, A. Sharma, P. Kumar, B. Singh, S. Ghosh, Charge transport mechanism in copper phthalocyanine thin films with and without traps, RSC Adv. 7 (2017) 54911-54919. https://doi.org/10.1039/C7RA08316E.

[3] H. Alves, A.S. Molinari, H. Xie, A.F. Morpurgo, Metallic conduction at organic chargetransfer interfaces, Nat. Mater. 7 (2008) 574-580. https://doi.org/10.1038/nmat2205.

[4] P.K. Nayak, R. Rosenberg, L. Barnea-Nehoshtan, D. Cahen, $\mathrm{O}_{2}$ and organic semiconductors: Electronic effects, Org. Electron. $14 \quad$ (2013) 966-972. https://doi.org/10.1016/j.orgel.2013.01.020.

[5] A. Litke, E.J.M. Hensen, J.P. Hofmann, Role of dissociatively adsorbed water on the formation of shallow trapped electrons in $\mathrm{TiO}_{2}$ photocatalysts, J. Phys. Chem. C 121(18) (2017) 10153-10162. https://doi.org/10.1021/acs.jpcc.7b01151. 
[6] A. Kumar, R. Meunier-Prest, M. Bouvet, Organic heterojunction devices based on phthalocyanines: A new approach to gas chemosensing, Sensors 20(17) (2020) 4700. https://doi.org/10.3390/s20174700.

[7] S. Ouedraogo, R. Meunier-Prest, A. Kumar, M. Bayo-Bangoura, M. Bouvet, Modulating the electrical properties of organic heterojunction devices based on phthalocyanines for ambipolar sensors, ACS Sens. 5(6) (2020) 1849-1857.

https://doi.org/10.1021/acssensors.0c00877.

[8] Z. Şahin, R. Meunier-Prest, F. Dumoulin, A. Kumar, Ü. Isci, M. Bouvet, Tuning of organic heterojunction conductivity by the substituents' electronic effects in phthalocyanines for ambipolar gas sensors, Sens. Actuators, $\quad$ B $332 \quad$ (2021) 129505. https://doi.org/10.1016/j.snb.2021.129505.

[9] H. Fan, W. Shi, X. Yu, J. Yu, High performance nitrogen dioxide sensor based on organic field-effect transistor utilizing ultrathin CuPc/PTCDI-C8 heterojunction, Synth. Met. 211 (2016) 161-166. https://doi.org/10.1016/j.synthmet.2015.11.021.

[10] S. Ji, H. Wang, T. Wang, D. Yan, A high-performance room-temperature $\mathrm{NO}_{2}$ sensor based on an ultrathin heterojunction film, Adv. Mater. 25(12) (2013) 1755-1760. https://doi.org/10.1002/adma.201204134.

[11] W. Huang, K. Besar, R. LeCover, A.M. Rule, P.N. Breysse, H.E. Katz, Highly sensitive $\mathrm{NH}_{3}$ detection based on organic field-effect transistors with tris(pentafluorophenyl)borane as receptor, J. Am. Chem. Soc. 134(36) (2012) 14650-14653. https://doi.org/10.1021/ja305287p.

[12] V. Parra, J. Brunet, A. Pauly, M. Bouvet, Molecular semiconductor-doped insulator (MSDI) heterojunctions: an alternative transducer for gas chemosensing, Analyst 134(9) (2009) 1776-1778. https://doi.org/10.1039/B906786H. 
[13] M. Mateos, R. Meunier-Prest, J.-M. Suisse, M. Bouvet, Modulation of the organic heterojunction behavior, from electrografting to enhanced sensing properties, Sens. Actuators, B 299 (2019) 126968. https://doi.org/10.1016/j.snb.2019.126968.

[14] A. Wannebroucq, S. Ouedraogo, R. Meunier-Prest, J. M. Suisse, M. Bayo, M. Bouvet, On the interest of ambipolar materials for gas sensing, Sens. Actuators, B 258 (2018) 657664. https://doi.org/10.1016/j.snb.2017.11.146.

[15] Z. Şahin, R. Meunier-Prest, F. Dumoulin, Ü. Işci, M. Bouvet, Alkylthio-tetrasubstituted $\mu$-nitrido diiron phthalocyanines: spectroelectrochemistry, electrical properties, and heterojunctions for ammonia sensing, Inorg. Chem. 59(2) (2020) 1057-1067. https://doi.org/10.1021/acs.inorgchem.9b02520.

[16] P. Gaudillat, A. Wannebroucq, J. M. Suisse, M. Bouvet, Bias and humidity effects on the ammonia sensing of perylene derivative/lutetium bisphthalocyanine MSDI heterojunctions, Sens. Actuators, B 222 (2016) 910-917. https://doi.org/10.1016/j.snb.2015.09.015.

[17] M. Mateos, M. D. Tchangaï, R. Meunier-Prest, O. Heintz, F. Herbst, J. M. Suisse, M. Bouvet, Low conductive electrodeposited poly(2,5-dimethoxyaniline) as a key material in a double lateral heterojunction, for Sub-ppm ammonia sensing in humid atmosphere, ACS Sens. 4(3) (2019) 740-747. https://doi.org/10.1021/acssensors.9b00109.

[18] M. Mateos, R. Meunier-Prest, O. Heintz, F. Herbst, J. M. Suisse, M. Bouvet, Comprehensive study of poly(2,3,5,6-tetrafluoroaniline): From electrosynthesis to heterojunctions and ammonia sensing, ACS Appl. Mater. Interfaces 10(23) (2018) 1997419986. https://doi.org/10.1021/acsami.8b03601. 
[19] R. Paolesse, S. Nardis, D. Monti, M. Stefanelli, C. Di Natale, Porphyrinoids for chemical sensor applications, Chem. Rev. 117(4) (2017) 2517-2583.

https://doi.org/10.1021/acs.chemrev.6b00361.

[20] Y. Wang, P. Ma, F. Song, S. Yao, C. Chen, P. Zhu, Comparative $\mathrm{NO}_{2}$-sensing in cobalt and metal-free porphyrin nanotubes, J. Colloid Interface Sci. 490 (2017) 129-136. https://doi.org/10.1016/j.jcis.2016.11.028.

[21] F. Song, P. Ma, C. Chen, J. Jia, Y. Wang, P. Zhu, Room temperature $\mathrm{NO}_{2}$ sensor based on highly ordered porphyrin nanotubes, J. Colloid Interface Sci. 474 (2016) 51-57. https://doi.org/10.1016/j.jcis.2016.04.012.

[22] K. Garg, A. Singh, C. Majumder, S.K. Nayak, D.K. Aswal, S.K. Gupta, S. Chattopadhyay, Room temperature ammonia sensor based on jaw like bis-porphyrin molecules, Org. $\quad$ Electron. 14(4) (2013) 1189-1196. https://doi.org/10.1016/j.orgel.2013.01.033.

[23] K. Garg, A. Singh, A.K. Debnath, S.K. Nayak, S. Chattopadhyay, D.K. Aswal, Y. Hayakawa, S.K. Gupta, J.V. Yakhmi, Bis-porphyrin films as ppb level chemiresistive sensors, Chem. Phys. Lett. 488(1) (2010) 27-31. https://doi.org/10.1016/j.cplett.2010.02.008.

[24] P. Guo, G. Zhao, P. Chen, B. Lei, L. Jiang, H. Zhang, W. Hu, M. Liu, Porphyrin nanoassemblies via surfactant-assisted assembly and single nanofiber nanoelectronic sensors for high-performance $\mathrm{H}_{2} \mathrm{O}_{2}$ vapor sensing, ACS Nano 8(4) (2014) 3402-3411. https://doi.org/10.1021/nn406071f.

[25] M. Andersson, M. Holmberg, I. Lundström, A. Lloyd-Spetz, P. Mårtensson, R. Paolesse, C. Falconi, E. Proietti, C. Di Natale, A. D’Amico, Development of a ChemFET sensor with molecular films of porphyrins as sensitive layer, Sens. Actuators, B 77(1) (2001) 567-571. https://doi.org/10.1016/S0925-4005(01)00691-8. 
[26] G. Bengasi, R. Meunier-Prest, K. Baba, A. Kumar, A.L. Pellegrino, N.D. Boscher, M. Bouvet, Molecular engineering of porphyrin-tapes/phthalocyanine heterojunctions for a highly sensitive ammonia sensor, Adv. Electron. Mater. 6(12) (2020) 2000812. https://doi.org/10.1002/aelm.202000812.

[27] C.H. Devillers, P. Fleurat-Lessard, D. Lucas, The fully unsubstituted porphyrin: A comprehensive overview, in: K. M. Kadish, K. M. Smith and R. Guilard, Handbook of porphyrin science, World Scientific Publishing 2016, pp. 75-231.

\section{https://doi.org/10.1142/97898131495710002.}

[28] M.A. Vorotyntsev, D.V. Konev, C.H. Devillers, I. Bezverkhyy, O. Heintz, Magnesium(II) polyporphine: The first electron-conducting polymer with directly linked unsubstituted porphyrin units obtained by electrooxidation at a very low potential, Electrochim. Acta 55(22) (2010) 6703-6714. https://doi.org/10.1016/j.electacta.2010.06.001.

[29] A. Osuka, H. Shimidzu, meso, meso-Linked porphyrin arrays, Angew. Chem. Int. Ed. 36(1- 2) (1997) 135-137. https://doi.org/10.1002/anie.199701351.

[30] D.V. Konev, O.I. Istakova, O.A. Sereda, M.A. Shamraeva, C.H. Devillers, M.A. Vorotyntsev, In situ UV-visible spectroelectrochemistry in the course of oxidative monomer $\begin{array}{llll}\text { electrolysis, } & \text { Electrochim. } & \text { Acta } & 179 \quad \text { 315-325. }\end{array}$ https://doi.org/10.1016/j.electacta.2015.06.076.

[31] O.I. Istakova, D.V. Konev, O.A. Goncharova, A.E. Antipov, C.H. Devillers, M.A. Vorotyntsev, Electrochemical quartz crystal microbalance study of magnesium porphine electropolymerization process, J. Solid State Electrochem. 24(11) (2020) 3191-3206. https://doi.org/10.1007/s10008-020-04800-1. 
[32] A. Tsuda, H. Furuta, A. Osuka, Completely fused diporphyrins and triporphyrin, Angew. Chem. Int. Ed. 39(14) (2000) 2549-2552. https://doi.org/10.1002/1521$\underline{\text { 3773(20000717)39:14<2549::AID-ANIE2549>3.0.CO;2-A. }}$

[33] D.K. Dogutan, M. Ptaszek, J.S. Lindsey, Direct synthesis of magnesium porphine via 1formyldipyrromethane, J. Org. Chem. 72(13) (2007) 5008-5011.

\section{https://doi.org/10.1021/jo070532z.}

[34] C.H. Devillers, D. Lucas, A.K.D. Dime, Y. Rousselin, Y. Mugnier, Exploring the redox reactivity of magnesium porphine. Insight into the origins of electropolymerisation, Dalton Trans. 39(9) (2010) 2404-2411. https://doi.org/10.1039/B914916C.

[35] D.V. Konev, C.H. Devillers, K.V. Lizgina, T.S. Zyubina, A.S. Zyubin, L.A. MaiorovaValkova, M.A. Vorotyntsev, Synthesis of new electroactive polymers by ion-exchange replacement of $\mathrm{Mg}$ (II) by $2 \mathrm{H}^{+}$or $\mathrm{Zn}$ (II) cations inside $\mathrm{Mg}$ (II) polyporphine film, with their subsequent electrochemical transformation to condensed-structure materials, Electrochim. Acta 122 (2014) 3-10. https://doi.org/10.1016/j.electacta.2013.10.004.

[36] S.D. Rolle, C.H. Devillers, S. Fournier, O. Heintz, H. Gibault, D. Lucas, A glassy carbon electrode modified by a triply-fused-like Co(II) polyporphine and its ability for sulphite oxidation and detection, New J. Chem. 42(10) (2018) 8180-8189. https://doi.org/10.1039/C7NJ04370H.

[37] O.I. Istakova, D.V. Konev, A.S. Zyubin, C.H. Devillers, M.A. Vorotyntsev, Electrochemical route to Co(II) polyporphine, J. Solid State Electrochem. 20(11) (2016) 3189-3197. https://doi.org/10.1007/s10008-016-3397-y.

[38] G. Clarisse, M.T. Riou, Synthesis and characterization of some lanthanide phthalocyanines, Inorg. Chim. Acta 130(1) (1987) 139-144. 
https://doi.org/10.1016/S0020-1693(00)85943-5.

[39] D.V. Konev, C.H. Devillers, K.V. Lizgina, V.E. Baulin, M.A. Vorotyntsev, Electropolymerization of non-substituted $\mathrm{Mg}(\mathrm{II})$ porphine: Effects of proton acceptor $\begin{array}{llllll}\text { addition, } & \text { J. } & \text { Electroanal. } & \text { Chem. } & 737 & \text { (2015) }\end{array}$ https://doi.org/10.1016/j.jelechem.2014.09.018.

[40] G.L. Kikobo, A. Kumar, V. Vibhu, S. Ouedraogo, A. Deshotel, M. Mateos, R. MeunierPrest, M. Bouvet, Photon assisted-inversion of majority charge carriers in molecular semiconductor-based organic heterojunctions, J. Mater. Chem. C 9(14) (2021) 5008-5020. https://doi.org/10.1039/D0TC05828A.

[41] K.M. Kadish, E.V. Caemelbecke, Electrochemistry of Metalloporphyrins in Nonaqueous Media, in: Encyclopedia of Electrochemistry. https://doi.org/10.1002/9783527610426.bard090006.

[42] W. Barford, M. Marcus, Perspective: Optical spectroscopy in $\pi$-conjugated polymers and how it can be used to determine multiscale polymer structures, J. of Chem. Phys. 146(13) (2017) 130902. https://doi.org/10.1063/1.4979495.

[43] J.J. Piet, P.N. Taylor, B.R. Wegewijs, H.L. Anderson, A. Osuka, J.M. Warman, Photoexcitations of covalently bridged zinc porphyrin oligomers: Frenkel versus Wannier-Mott type excitons, J. Phys. Chem. B 105(1) (2001) 97-104. https://doi.org/10.1021/jp0030140.

[44] M. Kasha, H.R. Rawls, M. Ashraf El-Bayoumi, The exciton model in molecular spectroscopy, Pure Appl. Chem. 11(3-4) (1965) 371-392. https://doi.org/10.1351/pac196511030371. 
[45] G. Bussi, A. Ruini, E. Molinari, M.J. Caldas, P. Puschnig, C. Ambrosch-Draxl, Interchain interaction and Davydov splitting in polythiophene crystals: An ab initio approach, Appl. Phys. Lett.80(22) (2002) 4118-4120. https://doi.org/10.1063/1.1483905.

[46] M. Aydin, DFT and Raman spectroscopy of porphyrin derivatives: Tetraphenylporphine (TPP), Vib. Spectrosc. 68 (2013) 141-152. https://doi.org/10.1016/j.vibspec.2013.06.005.

[47] G. Gouadec, P. Colomban, Raman Spectroscopy of nanomaterials: How spectra relate to disorder, particle size and mechanical properties, Prog. Cryst. Growth Charact. Mater. 53(1) (2007) 1-56. https://doi.org/10.1016/j.pcrysgrow.2007.01.001.

[48] M.A. Vorotyntsev, D.V. Konev, C.H. Devillers, I. Bezverkhyy, O. Heintz, Electroactive polymeric material with condensed structure on the basis of magnesium(II) polyporphine, Electrochim. Acta 56(10) (2011) 3436-3442. https://doi.org/10.1016/i.electacta.2010.10.039.

[49] A.A. Hermas, M. Nakayama, K. Ogura, Enrichment of chromium-content in passive layers on stainless steel coated with polyaniline, Electrochim. Acta 50(10) (2005) 2001-2007. https://doi.org/10.1016/j.electacta.2004.09.008.

[50] D.M. Sarno, L.J. Matienzo, W.E. Jones, X-ray photoelectron spectroscopy as a probe of intermolecular interactions in porphyrin polymer thin films, Inorg. Chem. 40(24) (2001) 6308-6315. https://doi.org/10.1021/ic010315v.

[51] S. Muralidharan, R.G. Hayes, Intense satellites in the N1s x-ray photoelectron spectra of certain metalloporphyrins, J. Am. Chem. Soc. 102(15) (1980) 5106-5107. https://doi.org/10.1021/ja00535a052.

[52] J.M. Gottfried, K. Flechtner, A. Kretschmann, T. Lukasczyk, H.-P. Steinrück, Direct synthesis of a metalloporphyrin complex on a surface, J. Am. Chem. Soc. 128(17) (2006) 5644-5645. https://doi.org/10.1021/ja0610333. 
[53] M.S. Killian, J.-F. Gnichwitz, A. Hirsch, P. Schmuki, J. Kunze, ToF-SIMS and XPS studies of the adsorption characteristics of a Zn-porphyrin on $\mathrm{TiO}_{2}$, Langmuir 26(5) (2010) 3531-3538. https://doi.org/10.1021/la9032139.

[54] J. Roncali, Synthetic principles for bandgap control in linear $\pi$-conjugated systems, Chem. Rev. 97(1) (1997) 173-206. https://doi.org/10.1021/cr950257t.

[55] K.A. Miller, R.D. Yang, M.J. Hale, J. Park, B. Fruhberger, C.N. Colesniuc, I.K. Schuller, A.C. Kummel, W.C. Trogler, Electrode independent chemoresistive response for cobalt phthalocyanine in the space charge limited conductivity regime, J. Phys. Chem. B 110(1) (2006) 361-366. https://doi.org/10.1021/jp053104a.

[56] B. Hirschorn, M.E. Orazem, B. Tribollet, V. Vivier, I. Frateur, M. Musiani, Determination of effective capacitance and film thickness from constant-phase-element parameters, Electrochim. Acta 55(21) (2010) 6218-6227. https://doi.org/10.1016/j.electacta.2009.10.065.

[57] Z. Lukács, Evaluation of model and dispersion parameters and their effects on the formation of constant-phase elements in equivalent circuits, J. Electroanal. Chem. 464(1) (1999) 68-75. https://doi.org/10.1016/S0022-0728(98)00471-9.

[58] Z. Lukács, The numerical evaluation of the distortion of EIS data due to the distribution of parameters, J. Electroanal. Chem. 432(1) (1997) 79-83. https://doi.org/10.1016/S0022$\underline{0728(97) 00217-9 .}$

[59] K.M. Lau, J.X. Tang, H.Y. Sun, C.S. Lee, S.T. Lee, D. Yan, Interfacial electronic structure of copper phthalocyanine and copper hexadecafluorophthalocyanine studied by photoemission, Appl. Phys. Lett. 88(17) (2006) 173513. https://doi.org/10.1063/1.2198484. 
A. Kumar et al. Chem. Eng. J. 2021, DOI 10.1016/j.cej.2021.132453

[60] I. Langmuir, the adsorption of gases on plane surfaces of glass, mica and platinum, J. Am. Chem. Soc. 40(9) (1918) 1361-1403. https://doi.org/10.1021/ja02242a004. 